\title{
De partido transitorio a partido permanente: el Partido Por la Democracia más allá de los mitos*
}

\author{
Daniel Grimaldi**
}

\begin{abstract}
Resumen
Este artículo intenta ir más allá de las representaciones sociales sobre el Partido Por la Democracia (PPD) que abogan por la tesis de un partido nuevo, el cual nace como "instrumental" para luego "cobrar vida propia". Mediante el análisis de entrevistas en profundidad así como de los resultados de una encuesta sociográfica aplicada a los consejeros del partido en el 2006, el autor plantea que el tránsito del PPD hacia su consolidación está guiado por dos grandes lógicas de militancia, las cuales permiten dar cuenta del paso de partido transitorio a duradero: la "lógica de la lucha épica" y la "lógica de la oportunidad". Esta última logra imponerse paulatinamente por sobre la segunda, generando un partido con una dirigencia altamente estatizada.
\end{abstract}

Palabras clave: PPD - partidos políticos - militancia - participación política - ideología.

\begin{abstract}
This paper aims at going beyond the social representations about the Party For Democracy (PPD), which plead for the thesis of a new party, first born as an "instrumental party", and which then "took on a life of its own". By means of in depth interviews analysis as well as the results of a sociographic survey applied to the PPD national counselors in 2006, the author shows that PPD's consolidation is guided by two logics of engagement, the "logic of epic struggle" and the "logic of opportunity". This last one gets/starts to prevail gradually over the first, producing a political party with a leadership highly dependent on the State.
\end{abstract}

Keywords: PPD - political parties - militancy - political participation - ideology.

* Este artículo se enmarca en los proyectos de investigación FONDECYT № 1061034, ECOS-CONICYT C05H01 y VID SOC07/29-02, en los cuales el autor se desempeñó como tesista. Mis agradecimientos a María de los Ángeles Fernández y Alexis Gutiérrez por sus comentarios y críticas a este artículo, cuyo resultado final es sin embargo de exclusiva responsabilidad del autor.

** Administrador Público de la Universidad de Chile y Máster en Sociología e Instituciones Políticas, Universidad de París 1 Panthéon-Sorbonne. Doctorando en Estudios Políticos de L'École de Hautes Études en Sciences Sociales (EHESS), París, Francia. Correo electrónico: danielgrimaldi@hotmail.com 


\section{INTRODUCCIÓN}

Hasta hoy, el Partido Por la Democracia (PPD) ha sido explicado mayoritariamente mediante la difusión de dos supuestos bastante consolidados entre los políticos y en el campo periodístico: a) el PPD es un partido instrumental; y b) el PPD es un partido sin ideología. En efecto, la idea de partido nuevo que nace como instrumental y luego cobra vida propia es bastante recurrente en trabajos importantes sobre el sistema de partidos en Chile ${ }^{1}$. Sin embargo, esta fórmula aparentemente útil para explicar el surgimiento del PPD no ha entregado ninguna relación de variables que puedan dar cuenta de las lógicas y dinámicas de tal proceso de transformación de "partido instrumental" a "partido real"2, ni la expresión aunque sea mínima de su ideología.

Para contrastar esta visión parcial, una forma de interrogar este partido político es por medio del análisis de las dinámicas del engagement de quienes sostienen al partido. ¿Cuáles son las formas del compromiso político en el PPD que nos hablan de transformaciones del espacio o política partidaria? Bajo esta pregunta podemos abordar dos aspectos cruciales sobre el PPD: primero su paso de partido transitorio a partido duradero; y segundo, la presencia y el rol de la ideología en el partido. Ésta es otra manera, a nuestro juicio más clara, de preguntarse qué es el PPD y con ello avanzar en el conocimiento sobre los procesos de transformación de las organizaciones políticas bajo formas de partido. Tal objetivo es el centro de este trabajo.

En esta primera parte nos situaremos en la problemática en torno al partido y en la discusión actual sobre las "transformaciones de la militancia"; en la segunda abordaremos el proceso de transformación del partido en una visión diacrónica para en la tercera concentrarnos en el análisis de la cuestión de la ideología en el PPD. Esta aproximación al estudio del PPD se basa en el análisis de entrevistas en profundidad a cuadros y dirigentes del partido, así como en los datos de una encuesta sociográfica ${ }^{3}$ aplicada a éstos en el año 2006 durante el Consejo Nacional del partido. También consideramos el análisis de material escrito, más la observación directa y participante.

\subsection{Problematizar lo "instrumental"}

Los partidos, como los define Max Weber (1964), son un instrumento para la realización de fines materiales e inmateriales. Ostrogorski antes que Weber ya había puesto de manifiesto

1 Garretón (1990); Bhöme y Barrera (1991); Valenzuela (1993,1995); Angell (1993); Boeninger (1997); Alcántara (2000); Heine (2003).

2 Samuel Valenzuela, al utilizar este término para mostrar que el PPD de 1987 no era un partido real dada su instrumentalidad, instala una interpretación que no se aclara en ningún momento. Véase Valenzuela (1995: 71).

La encuesta fue aplicada por un equipo compuesto por Alexis Gutiérrez, William Peters, Ledly Henríquez y Daniel Grimaldi, bajo la dirección de Hélène Combes, entonces profesora de la Universidad de París 1 Panthéon-Sorbonne. La encuesta fue aplicada el 25 de noviembre de 2006, recibiendo 241 respuestas de las cuales 182 fueron consejeros, 14 miembros de la directiva nacional, 34 invitados fraternales y 11 en otra calidad. 
una dimensión utilitarista de los partidos utilizando el concepto de "máquinas partidarias"4; la instrumentalidad, con o sin ideología, sería entonces un elemento presente en todos los partidos políticos bajo diferentes formas y contextos.

Si la "instrumentalidad" originaria del PPD estaba dada en razón de su objetivo particular en el marco de la transición política, debemos recordar que este partido dejó de ser un "partido instrumental-transitorio" en un breve plazo (1987-1990), por tanto esta "instrumentalidad" es poco precisa para definir al partido en su desarrollo posterior. Existió otro partido designado igualmente como "instrumental" paralelo al PPD, el Partido Amplio de Izquierda Socialista (PAIS), que luego se disolvió tras la elección de 1989, lo que nos habla de grandes diferencias entre un proyecto que fue realmente transitorio y otro que presentó características que lo hicieron durable.

A partir de la "crisis del PPD" en el 2007 se han escuchado con mayor fuerza las tesis del "partido sin ideología" (Peña, 2006; Huneeus, 2007), que sería la causa de las crisis internas por la que ha atravesado el partido, con divisiones, expulsiones y renuncias de dirigentes fundadores y militantes destacados. Sin embargo, crisis muy semejantes han sido experimentadas por otros partidos sin supuestamente esta falta de ideología ${ }^{5}$. Ciertamente, hoy el concepto de ideología está totalmente relativizado y su declive es una característica general en las organizaciones partidarias (Dalton y Wattenberg, 2000). Sin embargo, todo partido tiene en su seno expresiones de pensamiento, estructuraciones ideológicas de diferente intensidad más o menos cristalizadas. Esto nos lleva a pensar que es más fructífero mirar al interior del partido y observar las formas evidentes y solapadas de posiciones ideológicas, sus mecanismos de reproducción y su encarnación en la política partidaria. Bajo una nebulosa ideológica del "partido como un todo" pueden existir corrientes más definidas en su interior (Haegel, 2007: 219), tomando forma de fracciones, facciones o tendencias ${ }^{6}$.

Estos supuestos han dado origen en Chile a dos clasificaciones interesantes sobre el PPD. Por parte de Heine (2002) la de "partido profesional-electoral", siguiendo la clasificación de Panebianco, y la de "partido de notables", de la clasificación de Max Weber según Huneeus (2002). Sin embargo, ambas clasificaciones están basadas en aspectos parciales del partido. Para Heine, el PPD representa una nueva forma de hacer política, partido mediatizado, moderno, concentrado en los liderazgos, mientras que para Huneeus el caciquismo y el patronazgo de los líderes del PPD lo acercaría al modelo de partido de notables, antiguo y oligárquico.

4 Ostrogorski (1912: 483). Sobre esta base, Alcántara clasifica al PPD, entre otros partidos de Latinoamérica, como "partido máquina electoral". Véase Alcántara (2001).

5 Casos similares donde ha habido acusaciones de corrupción, expulsiones, renuncias y divisiones se han dado en el Partido Socialista y la Democracia Cristiana. La expulsión del senador democratacristiano Adolfo Zaldívar es muestra de aquello.

6 Consideramos una facción como un grupo de poder al interior del partido basado en intereses particulares. Una tendencia es un conjunto de actitudes que pueden ser más o menos estructuradas políticamente. Una fracción es una división interna partidaria organizada y con cierta disciplina. Para el detalle de estas definiciones, véase Sartori (2002: cap. IV). 
A nuestro juicio ambas concepciones son correctas, sin embargo parciales. Sobre el PPD podríamos decir que tiene una herencia de partido de masas en lo estructural debido a su semejanza organizacional con el Partido Socialista (PS) y una estructura ideológica del tipo catch-all según el modelo de Kirchheimer (1990), con un repertorio valórico amplio y un electorado objetivo pluriclasista. Por ende, si un partido como el PPD contiene varias clasificaciones en diferentes dimensiones, queda de manifiesto la debilidad explicativa de tales clasificaciones más allá de constituir "tipos ideales", los que difícilmente tienen una existencia en una forma pura. Ello nos motiva a avanzar en otras fuentes explicativas.

Al margen de la crítica criolla sobre qué tan mal lo hacen los partidos o sobre su "calidad", lo cierto es que la actividad política hoy, en Chile y el mundo, parece no estar en buen pie respecto a la evaluación de los ciudadanos; tal vez nunca lo ha estado, pero hoy existen índices ${ }^{7}$ de descontento con los partidos que nos llaman a indagar acerca de las transformaciones de los partidos en los últimos años, y con ello el conjunto de relaciones sociales que los reproducen. Las transformaciones del "compromiso político" en su forma de militancia nos conducen a observar los fenómenos presentes en la metamorfosis de las organizaciones partidistas. Por lo tanto, para resolver cuestiones relativas a la naturaleza y especificidad del PPD creemos que un análisis de las transformaciones de la participación política en su seno nos puede dar luces sobre de qué tipo de organización estamos hablando cuando nos referimos al PPD, más allá de los mitos y simplificaciones.

\subsection{Las transformaciones de la militancia}

La tradición de la ciencia política a partir de Duverger considera como "militante" al individuo que posee una inversión mayor de tiempo, recursos, trabajo personal, esperanzas y expectativas depositadas en el partido respecto a un simple adherente que firma la ficha de ingreso (Duverger, 1990: 175). Al conjunto de esta inversión podemos denominarla "compromiso político". También se tiende a diferenciar a los "dirigentes" de los "militantes", entre otras cosas en relación a la cadena de mando y obediencia en el partido y a una cierta división del trabajo. Nosotros optamos, sin embargo, por un uso de la noción de "militantes" en un sentido extensivo a los dirigentes y cuadros.

En efecto, si consideramos a los partidos como sistemas de dominación ${ }^{8}$-en términos de Weber- no podemos olvidar que los dirigentes están sometidos igualmente a una escala de dominación y jerarquía donde su posición de dirigente es dinámica y está sometida a múltiples dominaciones y juegos de poder. Existen dirigentes locales y regionales que hacen igualmente tareas de campaña como los demás militantes "sin rango". También los altos dirigentes de partidos de gobierno constantemente deben responder con disciplina a los lineamientos del presidente de la República, por ejemplo, o a las indicaciones de grupos

7 Según las series de encuestas Centro de Estudios Públicos (CEP), el nivel de confianza de los ciudadanos en los partidos es el más bajo entre todas las instituciones. Véase www.cepchile.cl

8 "La probabilidad de encontrar obediencia en un grupo determinado para mandatos específicos (o todo tipo de mandatos)" (Weber, 1964: 170). 
religiosos o empresariales en el caso de partidos confesionales o representantes de la derecha económica. En segundo lugar, considerar que la militancia o la noción de militante está ligada exclusivamente a una forma partidaria como la de partidos de masa implica una cierta visión estática de la actividad militante, que conlleva a posiciones como creer que el "verdadero partido de militantes" es el partido de masa, dejando de lado otras expresiones de la actividad política partidaria.

Con todo, hoy la militancia política estaría sujeta a fuertes transformaciones, que junto con poner en tabla la disminución de la cantidad de militantes, ponen en interrogación el concepto mismo, puesto que "al mismo tiempo que las formas de compromiso se diversifican, la definición misma de militancia se vuelve plural" (Ion, 2007).

Jacques lon (2001: 23-34) observa que los cambios en la militancia están guiados por un proceso de emancipación (affranchissement) de los antiguos esquemas que determinaban la militancia tradicional. Así, hoy estaríamos en presencia de dos tipos de militante: el "militante comprometido" 9 (affilié), representante de la antigua visión ligada a los partidos sobre todo ideológicos, y el "militante emancipado" o distanciado (affranchi), más libre y no ligado permanentemente a las organizaciones, sino que ejerce su compromiso político de manera a veces intermitente y para momentos y tareas específicas, lo que lon llama militante post-it. Estos militantes serían el modelo de participación dentro de los nuevos movimientos sociales, agrupaciones de voluntariado, altermundistas, etc. El proceso de emancipación según el autor llevaría al "fin de los militantes" a la manera tradicional. La claridad de lon para mostrar los cambios en las nuevas militancias trae a la vez una sombra respecto a los cambios en la militancia comprometida, es decir, que la aparición de nuevas militancias no da por sí misma la explicación de cambios en la militancia comprometida.

Susan Scarrow (2000, en Dalton y Wattenberg, 2000: 79-101) muestra los resguardos que se debe tener a la hora de hablar del debilitamiento de la militancia en los partidos políticos, puesto que la disminución de militantes no significa necesariamente que la militancia sea débil. Pueden existir menos militantes, pero a la vez más comprometidos con sus organizaciones, más dependientes y enraizados en la estructura partidaria. El modelo del "partido cartel" de Katz y Mair (1995) en cierta medida da cuenta de este fenómeno de militantes dependientes del partido y del aparato estatal, donde el partido sería una agencia de proveedores de "servicios de representación"; sin embargo esta visión es igualmente parcial y sólo muestra una tendencia en los partidos políticos occidentales.

La sociología de la acción colectiva y de la militancia ha consagrado importantes trabajos al estudio de los móviles que determinan la adhesión a organizaciones y causas determinadas

9 La traducción literal del francés es el término "afiliado", pero hemos decidido cambiarlo por "comprometido" dado el riesgo de confundir el concepto con el término legal de afiliado según la ley de partidos políticos chilena. 
más allá de los sentimientos de solidaridad con la causa común ${ }^{10}$. En esta línea, para el caso de la militancia política, Daniel Gaxie (1977) ha puesto en evidencia la relatividad de los móviles ideológicos e instaurado un análisis de la militancia que se centra en las estructuras de oferta que brindan los partidos a los potenciales militantes. Esta oferta configura un repertorio de beneficios asociados al hecho de involucrarse y militar en un partido durante un período de tiempo determinado (Gaxie, 2005: 179), lo que nos permite identificar móviles para el compromiso partidario analizando la oferta del partido.

Los partidos transitan hacia su consolidación ${ }^{11}$ mediante la gestión de sus recursos disponibles como la sigla o marca, su capital financiero, sus redes con organizaciones de base y/o grupos de interés, los puestos que poseen en el Estado, sus militantes, los liderazgos y su electorado, de manera de imponerse en el campo político e incrementar su poder (Offerlé, 2002: 26). Este tránsito desde el nacimiento hasta la consolidación contiene dinámicas específicas relacionadas con elementos del contexto político, con las oportunidades que el partido presenta y los intereses de quienes lo componen, elementos que puestos en marcha generan la reproducción de la organización mediante lo que denominaremos lógica(s) de militancia.

A partir de este marco de análisis, nuestro caso de estudio puede abrir espacio para develar algunas interrogantes sobre las transformaciones de la militancia en relación a la evolución de la oferta de un partido en forma diacrónica desde su fundación. De esta forma, podemos desarrollar aspectos que nos permitan comprender el paso de "partido transitorio" a "partido permanente", y en ello esclarecer el rol de la ideología en la reproducción del partido.

¿Cuáles son las lógicas de reproducción del PPD?, ¿cuál es el lugar de la ideología en la militancia política hoy en el PPD?

\section{LA LUCHA ÉPICA Y LA OPORTUNIDAD POLÍTICA: DOS LÓGICAS DE MILITANCIA}

EI PPD en estricto rigor no es un partido nuevo si consideramos que tanto sus miembros como sus postulados no son propiamente producto de la coyuntura de la transición, sino que se inscriben en un proceso anterior conocido como la renovación del socialismo y la división del PS en 1979 entre ortodoxos y renovados: PS-Almeyda y PS-Altamirano, respectivamente. Tras un proceso frustrado de unificación durante los años ochenta, ambas fracciones enfrentan el plebiscito de 1988 con estrategias distintas (Arrate y Rojas, 2003:

10 Mediante el estudio de los sindicatos en Estados Unidos, Olson construye el dilema del free rider o "dilema del polisón" basado en aquellos individuos cuya estrategia es profitar de los beneficios alcanzados por la organización; por ejemplo, los huelguistas que no participan ni asumen los costos de las acciones. Esta sería un estrategia común en los seres humanos, por lo cual los movimientos colectivos de gran volumen están destinados al fracaso salvo en casos en que existan incentivos particulares para ciertos miembros por el hecho de adherir. Véase Olson (1971).

11 Consideramos "consolidación de un partido" cuando éste se instala en el sistema de partidos como un actor relevante, por su peso electoral, su nivel de influencia, su "capacidad de chantaje" o su poder militar. Para una extensión del criterio de relevancia de los partidos, véase Sartori (2002). 
cap. 8). El PS renovado liderado posteriormente por Ricardo Núñez crea el PPD sobre la base de una idea de Ricardo Lagos, Ilamando a la unidad de todos quienes estuviesen contra la dictadura sin importar su pensamiento ideológico. La discusión ideológica debía realizarse posteriormente una vez recuperada la democracia:

“El PPD no caerá en un debate entre los opositores. ¡No! Nuestro único norte es enfrentarnos organizada y políticamente a la dictadura. Convertirnos en un instrumento para derrotarla (...). Mañana, restablecida la democracia, será el momento de plantear al país lo que piensa cada uno de nosotros. Entonces el Partido Por la Democracia habrá cumplido su meta, la democracia estará restaurada"12.

Por su parte, el PS-Almeyda crearía el PAIS junto al Partido Comunista (PC) y otros partidos pequeños de izquierda; desde aquí se tenía una opinión muy crítica respecto al PPD, que lejos de ver en él su carácter no ideológico fue considerado como una estrategia del socialismo renovado:

"Estamos por discutir una iniciativa opositora unitaria no excluyente, pero consideramos que la idea del PPD nació excluyente. Es más, creemos que el objetivo final de este PPD es meterse en el sistema y no, como lo presentan, en el sentido de ser un partido instrumental. Pensamos que éste es el punto de protagonismo político que necesitaba el PS-Núñez al momento de lanzar la iniciativa, porque estaba perdiendo imagen propia, al salir de la Alianza Democrática y al no integrar la Izquierda Unida"13.

Este partido heredero del socialismo renovado, a diferencia del PAIS, no fue disuelto tras la recuperación de la democracia, sino que tuvo una transformación que lo llevó a superar su fecha de caducidad. El "todo PPD" fue mucho más que la suma de sus partes: generó espacios de participación, expectativas, esperanzas, retribuciones, una imbricación de intereses de largo alcance en su interior y un éxito electoral considerable.

El partido debió generar una institucionalidad, crear sedes regionales y comunales, activar comandos territoriales, sumar adherentes mediante la recolección de firmas, toda una enorme tarea de instalación mediante la cual se establecieron nexos objetivos y afectivos de implantación, que posteriormente fueron muy difíciles de disolver. Por otra parte, la efervescencia misma del proceso generó un clima de alta politización ${ }^{14}$ favorable a la oposición debido a la claridad del enfrentamiento entre la continuidad o la salida del régimen militar, y la definición de "lo político" en términos de amigo-enemigo (Schmitt, 1999). En este contexto los líderes del PPD aprovecharon de mediatizar la contienda con la aparición de Ricardo Lagos en televisión encarando y apuntando con el dedo a Pinochet, enrostrándole querer perpetuarse en el poder y darle al país 25 años de dictadura, tortura y

12 Ricardo Lagos, Discurso de Fundación del PPD en el Círculo Español, pronunciado el 15 de diciembre de 1987.

13 Declaración de Clodomiro Almeyda, citada en Arrate y Rojas (2003: 463).

14 Según la encuesta CEP de agosto de 1987, el 27\% de la población se declaró muy interesado y el $47 \%$ algo interesado en los comicios del sí y el NO. 
muertes. Éste fue un hecho de alto impacto en la imagen de Ricardo Lagos y del PPD, desde donde pueden apreciarse ciertos rasgos mediáticos en su origen.

Podemos verificar el rol de la efervescencia del proceso político y el papel de dirigentes como Ricardo Lagos como factores decisivos para la adhesión al PPD entre nuestros encuestados que ingresaron al partido entre los años 1987 y 1989. El Cuadro 1 indica que un $71,8 \%$ declara haber adherido al PPD dado el contexto político del momento, y vemos que esta cifra baja considerablemente a 35,5\% entre quienes lo hacen después de 1990, una vez pasado el período de mayor efervescencia. Por otra parte, el trabajo en organizaciones sociales y la admiración de ciertas figuras políticas son factores importantes en la adhesión, los cuales presentan una baja variación en los años posteriores a la fundación del partido.

\section{CUADRO 1}

Factores de "mucha importancia" para adherir al PPD entre militantes que ingresaron en el período 1987-1989 y después de 1989

\begin{tabular}{|l|c|c|}
\hline \multicolumn{1}{|c|}{ FACTORES DE LA ADHESIÓN AL PPD } & ENTRE 1987 Y 1989 & DESPUÉS DE 1989 \\
\hline Miembros de mi familia & $7,8 \%$ & $8,0 \%$ \\
\hline Algunos amigos & $6,8 \%$ & $5,8 \%$ \\
\hline Contacto directo con algunos militantes del PPD & $7,8 \%$ & $10,9 \%$ \\
\hline Políticos que yo admiraba & $22,3 \%$ & $20,3 \%$ \\
\hline Líderes de mi iglesia & $3,9 \%$ & $0,7 \%$ \\
\hline Contexto político del momento & $71,8 \%$ & $35,5 \%$ \\
\hline La acción del partido en mi trabajo o lugar de estudio & $3,9 \%$ & $3,6 \%$ \\
\hline $\begin{array}{l}\text { Mi experiencia de trabajo en organizaciones sociales } \\
\text { fuera del partido }\end{array}$ & $23,3 \%$ & $21,0 \%$ \\
\hline Otra & $2,9 \%$ & $10,1 \%$ \\
\hline
\end{tabular}

Fuente: Encuesta a consejeros del PPD (2006), Proyecto FONDECYT 1061034.

En su composición inicial, del PPD se ha dicho que concitó la atención de adherentes de todo tipo de ideologías, incluso de la derecha liberal (aunque en un porcentaje marginal), al igual que de una parte de miembros de organizaciones de la sociedad civil que le darían su carácter de "partido ciudadano". Este punto daría al PPD un discurso y una imagen para contener a un nuevo tipo de militancia emergente desde las organizaciones sociales, más "emancipada", intermitente y distanciada de las estructuras partidarias rígidas como lo señala 
Jacques lon. De hecho, el término "militante" en el PPD tiene una utilización confusa ya que no existe como categoría específica en los estatutos, a diferencia de lo que sucede en el PS y la Democracia Cristiana (DC). El PPD aplica más bien la nomenclatura de la ley de partidos políticos chilena ${ }^{15}$ asimilando el concepto de "afiliado" al de militante ${ }^{16}$. Igualmente, se hace una distinción de estos últimos con la figura de los "adherentes"17, quienes son considerados según los estatutos del PPD como colaboradores del partido sin estar inscritos. Es decir, en el momento en que se es aceptado como afiliado mediante la tramitación de la ficha de afiliación al partido, se adquiere la condición de militante en el PPD.

Esto muestra una forma laxa de utilización del concepto de "militante", posiblemente para atraer a quienes no deseaban pertenecer ni obedecer a estructuras de la vieja izquierda. Esta distinción sui generis del PPD contrasta fuertemente con las categorías de participación política de Duverger, donde el adherente es un "afiliado". Así, en el PPD la concepción del militante como una forma más comprometida de participación política no existe. Aún más, hay ciertos "adherentes" que tienen un rol de mayor importancia en comparación con los militantes dado su capital político ${ }^{18}$ e influencia ${ }^{19}$. Esta asimilación de la categoría de militante a la de miembro del partido es, según Duverger (1990), una característica muy común de los partidos de cuadros; sin embargo, asimilar al PPD a un partido de cuadros tampoco sería muy preciso, pues esto demuestra sólo una dimensión de la cultura interna en cuanto al uso del concepto de militante.

Como muestra el Cuadro 2 respecto a la militancia política anterior, un 25\% declaró en el 2006 no haber pertenecido antes del PPD a ningún otro partido. Este porcentaje eventualmente podrían ser militantes "ciudadanos" o de organizaciones sociales, datos que precisa el Cuadro 3, donde se puede ver una interesante conexión de los militantes del PPD con las organizaciones sociales en el pasado.

15 Ley № 18.603 Orgánica Constitucional de los Partidos Políticos.

16 "Son afiliados o militantes del PPD las ciudadanas y ciudadanos inscritos en los Registros Electorales que hayan suscrito la solicitud de afiliación y se encuentren incorporados al Registro Nacional de Afiliados" (Estatutos del PPD: art. 3).

17 "Podrán existir adherentes al partido, cuyo propósito fundamental es ayudar al cumplimiento del Programa y demás tareas de éste en sus diversos niveles, según corresponda. Las obligaciones y deberes para con el partido serán aquellas que libremente convengan con la estructura partidaria a la cual se adscriben. Existirá un registro especial de adherentes" (Estatutos del PPD: art. 5).

18 Según Pierre Bourdieu, en tanto esfera del capital simbólico podemos considerar al capital político como el "crédito basado en las innumerables operaciones de crédito por las cuales los agentes confieren a una persona socialmente designada como digna de crédito, los poderes mismos que le reconocen". Véase Bourdieu (1981).

19 Un caso clave es el de Carolina Tohá, quien no siendo afiliada al PPD fue una de sus fundadoras y Subsecretaria General de Gobierno con "cupo" PPD en la administración de Ricardo Lagos. Sólo posteriormente hizo su inscripción oficial en el partido. 


\section{CUADRO 2}

Partido de pertenencia antes del PPD (al 2006)

\begin{tabular}{|l|c|}
\hline \multicolumn{1}{|c|}{ PARTIDO } & PORCENTAJE \\
\hline Frente Patriótico Manuel Rodríguez (FPMR) & 0,5 \\
\hline Izquierda Cristiana (IC) & 4,5 \\
\hline Movimiento de Acción Popular Unitario (MAPU y MAPU Obrero Campesino) & 12,7 \\
\hline Movimiento de Izquierda Revolucionario (MIR) & 5,6 \\
\hline Partido Amplio de Izquierda Socialista (PAIS) & 3,1 \\
\hline Partido Comunista de Chile (PC) & 12,8 \\
\hline Partido Radical & 4,1 \\
\hline Partido Socialista de Chile (PS) & 11,2 \\
\hline PS-Almeyda & 3,6 \\
\hline PS-Altamirano & 7,7 \\
\hline Partido Demócrata Cristiano (PDC) & 3,6 \\
\hline Otro & 5,6 \\
\hline Ninguno & 25,0 \\
\hline
\end{tabular}

Fuente: Encuesta a Consejeros del PPD, Proyecto FONDECYT 1061034.

\section{CUADRO 3}

Militancia o participación en otras organizaciones fuera del PPD

\begin{tabular}{|l|c|c|c|}
\hline \multicolumn{1}{|c|}{ ORGANIZACIÓN } & $\begin{array}{c}\text { PARTICIPABA EN } \\
\text { ORGANIZACIONES } \\
\text { SOCIALES ANTES DE } \\
\text { MILITAR EN EL PPD }\end{array}$ & $\begin{array}{c}\text { PARTICIPABA EN } \\
\text { ORGANIZACIONES } \\
\text { SOCIALES Y A LA VEZ } \\
\text { MILITABA EN PARTIDOS } \\
\text { POLÍTICOS }\end{array}$ & $\begin{array}{c}\text { PARTICIPA EN LA } \\
\text { ACTUALIDAD EN } \\
\text { ORGANIZACIONES } \\
\text { SOCIALES }\end{array}$ \\
\hline Juntas de vecinos & $28,6 \%$ & $76,8 \%$ & $17,0 \%$ \\
\hline Clubes deportivos & $20,7 \%$ & $90 \%$ & $11,6 \%$ \\
\hline $\begin{array}{l}\text { Organizaciones o grupos } \\
\text { religiosos }\end{array}$ & $18,3 \%$ & $75 \%$ & $8,3 \%$ \\
\hline $\begin{array}{l}\text { Organizaciones } \\
\text { artístico-culturales }\end{array}$ & $15,8 \%$ & $80 \%$ & $8,3 \%$ \\
\hline
\end{tabular}




\begin{tabular}{|c|c|c|c|}
\hline ORGANIZACIÓN & $\begin{array}{l}\text { PARTICIPABA EN } \\
\text { ORGANIZACIONES } \\
\text { SOCIALES ANTES DE } \\
\text { MILITAR EN EL PPD }\end{array}$ & $\begin{array}{c}\text { PARTICIPABA EN } \\
\text { ORGANIZACIONES } \\
\text { SOCIALES Y A LA VEZ } \\
\text { MILITABA EN PARTIDOS } \\
\text { POLIITICOS }\end{array}$ & $\begin{array}{l}\text { PARTICIPA EN LA } \\
\text { ACTUALIDAD EN } \\
\text { ORGANIZACIONES } \\
\text { SOCIALES }\end{array}$ \\
\hline $\begin{array}{l}\text { Centros de padres y } \\
\text { apoderados }\end{array}$ & $20,7 \%$ & $76 \%$ & $7,9 \%$ \\
\hline $\begin{array}{l}\text { Centros de madres o talleres } \\
\text { para mujeres }\end{array}$ & $4,1 \%$ & $62,5 \%$ & $4,1 \%$ \\
\hline $\begin{array}{l}\text { Organizaciones de adultos } \\
\text { mayores }\end{array}$ & $3,3 \%$ & $66,6 \%$ & $3,3 \%$ \\
\hline $\begin{array}{l}\text { Comités de allegados o } \\
\text { habitacionales }\end{array}$ & $5,0 \%$ & $41,6 \%$ & $3,3 \%$ \\
\hline $\begin{array}{l}\text { Centros de alumnos de } \\
\text { secundaria }\end{array}$ & $41,5 \%$ & $74 \%$ & $2,5 \%$ \\
\hline $\begin{array}{l}\text { Federaciones de alumnos de } \\
\text { secundaria }\end{array}$ & $19,5 \%$ & $85 \%$ & $0,8 \%$ \\
\hline $\begin{array}{l}\text { Centros de alumnos de } \\
\text { educación superior }\end{array}$ & $25,3 \%$ & $91 \%$ & $2,5 \%$ \\
\hline $\begin{array}{l}\text { Federaciones de estudiantes } \\
\text { de educación superior }\end{array}$ & $20,7 \%$ & $90 \%$ & $1,7 \%$ \\
\hline Colegios profesionales & $14,1 \%$ & $94 \%$ & $7,1 \%$ \\
\hline $\begin{array}{l}\text { Agrupaciones gremiales de } \\
\text { comercio }\end{array}$ & $2,9 \%$ & $57,1 \%$ & $1,2 \%$ \\
\hline $\begin{array}{l}\text { Agrupaciones gremiales de } \\
\text { servicios }\end{array}$ & $3,3 \%$ & $50 \%$ & $0,4 \%$ \\
\hline $\begin{array}{l}\text { Agrupaciones gremiales de } \\
\text { productores }\end{array}$ & $1,7 \%$ & $66 \%$ & $1,7 \%$ \\
\hline Organizaciones sindicales & $8,7 \%$ & $100 \%$ & $6,2 \%$ \\
\hline ONGs & $6,2 \%$ & $80 \%$ & $7,5 \%$ \\
\hline
\end{tabular}

Fuente: Encuesta a Consejeros del PPD, Proyecto FONDECYT 1061034.

Podemos apreciar que el grueso de los militantes encuestados provenía de la izquierda de los años setenta, específicamente del PS, PC y el MAPU, teniendo a la vez una participación muy importante en organizaciones sociales de todo tipo. Dentro de estas organizaciones sociales, especialmente ONGs, sindicatos y colegios profesionales, se coordinaron operaciones políticas contra la dictadura y desde ahí se pudo reclutar para el PPD a quienes no provenían de los círculos de los partidos políticos. La siguiente entrevista nos ilustra al respecto y señala el potencial que vio Ricardo Lagos en este tipo de organizaciones, sobre todo las de derechos humanos ligadas a la Iglesia Católica, para poder alimentar y dar fuerza al PPD en el contexto de la transición: 


\begin{abstract}
"Me recuerdo que en el SERPA ${ }^{20}$ montamos un tipo de seminario de trabajo en la línea de derechos humanos y democracia, porque entendíamos que para que los derechos humanos se plasmaran en la democracia había que establecer un vínculo con los partidos (...) efectivamente en ese momento Lagos tira esta cosa de 'un gran referente', todo era grande todavía, no había este concepto de 'partido por', el concepto de partido por la democracia aparece en el 87 fuertemente, y como ya habíamos estrechado lazos con él y él ya visitaba relativamente nuestra sede e intercambiaba con nosotros, me recuerdo que cuando él hace esta invitación a formar los primeros procesos destinados a constituir el PPD, yo me acerco y le digo: don Ricardo yo quiero estar en esto colaborando, y me dijo: ¡por supuesto!, de una manera muy efusiva porque la incorporación del capital de activistas y dirigentes nacionales del mundo de los derechos humanos, además reconocidos por la Iglesia y organismos internacionales era para él... j'el capital'! (...) entonces era como que confluían dos vertientes en la formación de este proyecto; por un lado la sociedad civil y derechos humanos y por otro el ámbito de los partidos. Yo estuve entremedio de los dos mundos, entonces me metí con todo" 21 .
\end{abstract}

Si bien es cierto que un 25\% aproximadamente de los militantes encuestados no tenía una experiencia política anterior (Cuadro 2), de este porcentaje un 14\% participaba en organizaciones sociales ${ }^{22}$. Por lo tanto, nos queda un $11 \%$ que ni eran militantes políticos ni participaban en organizaciones sociales. Ello que no quiere decir que este grupo sea desideologizado como alguna vez se ha querido presentar, como veremos en la tercera parte de este trabajo. De todas formas, como muestra la tercera columna del Cuadro 3, la militancia social fue desapareciendo poco a poco para concentrarse durante la democracia en la actividad partidaria, dejando cada vez más desprovisto al PPD del componente "ciudadano".

Respecto a la pertenencia social de quienes fundaron el PPD, en el Cuadro 4 podemos apreciar que entre quienes firmaron el acta de fundación del partido predominaban aquellas personas provenientes de estratos socioprofesionales que poseen un capital cultural importante. Aquí destacan las profesiones intelectuales, liberales, los profesores y los artistas, que suman en su conjunto un $75,6 \%$. A pesar de lo anterior, no es correcto calificar al PPD en la lógica de los partidos de clase alta de derecha, puesto que tales partidos se componen preferentemente de un estrato alto integrado por grandes comerciantes e industriales y profesiones liberales, con un menor grado de presencia de profesiones intelectuales (Gaxie, 1980). Lo que sí es una evidencia clarísima es que el componente popular del PPD en su origen fue casi inexistente.

20 Servicio Paz y Justicia, organismo de defensa de los derechos humanos ligado a la Iglesia Católica.

21 Testimonio de "D", uno de los fundadores del PPD, trabajador social, ex militante de la DC y de la IC. Durante la dictadura su trabajo se concentró en organizaciones de derechos humanos al alero de la Iglesia Católica. Entrevista realizada en mayo del 2007.

22 Promedio de la frecuencia porcentual de quienes no tuvieron partido político antes del PPD, pero que sí participaban en organizaciones sociales mencionadas en el Cuadro 3. 


\section{CUADRO 4}

Composición socioprofesional de los miembros fundadores del PPD en 1987

\begin{tabular}{|l|c|c|}
\hline \multicolumn{1}{|c|}{ PROFESIONES/ESTRATOS } & NÚMERO & PORCENTAJE \\
\hline Profesiones liberales & 27 & 34,3 \\
\hline Profesiones intelectuales & 38 & 5,4 \\
\hline Artistas & 6 & 11,7 \\
\hline Profesores & 13 & 0,9 \\
\hline Comerciantes & 1 & 9,0 \\
\hline Empleados & 10 & 6,3 \\
\hline Técnicos & 7 & 0,9 \\
\hline Artesanos & 1 & 2,7 \\
\hline Pensionados & 3 & 0,9 \\
\hline Obreros & 1 & 3,6 \\
\hline Pobladores & 4 & 100 \\
\hline Totales & 111 & \\
\hline
\end{tabular}

Fuente: Elaboración propia en base a la nómina de fundadores del PPD.

El momento fundacional del PPD es un relato persistente en quienes se identifican con una cierta épica del contexto de la transición política. En el escenario de un plebiscito para decidir la salida del dictador, la situación era tan incierta que identificar claramente un móvil utilitarista del compromiso político resulta poco realista. En su momento fundacional el partido sumó adhesiones mucho más allá de las retribuciones materiales. La retribución se configuró más bien en términos simbólicos, que podemos identificar, por ejemplo, en cierta satisfacción de sentirse parte de la historia, ser partícipe de un proceso clave en la evolución política de Chile o simplemente sacar al dictador para generar mejores condiciones de vida. Ciertamente, bajo esta lógica posiblemente la salida del dictador podría permitir alcanzar en el futuro plataformas para retribuciones relacionadas con el poder político y la carrera militante, sin embargo tales aspiraciones no tenían un carácter inmediato. El clima de la campaña es el espacio privilegiado para aglutinar a los primeros militantes del PPD donde se generan los primeros lazos en la organización, como podemos ver en el testimonio siguiente: 


\begin{abstract}
"Yo estaba en esa época (1987) en el colegio, tercero o cuarto medio, y paralelamente junto con acompañarlo (a su padre) en la labor política, motivado por la cuestión política comencé a aportar mi granito de arena en lo que yo hacía en mi colegio, yo estudié en el Salesianos de Macul y ahí empezamos a activar junto con otros cabros de izquierda y socialistas y a incorporar a otros jóvenes. (...) Siendo del PS, cuando nació el PPD yo pasé a tener militancia inmediata en el partido y ese trasvasije de militantes lo hizo mi papá. Mi padre era dirigente de la brigada de profesores socialistas en la zona sur oriente de la capital, y comienza un trasvasije de militantes del PS al PPD para militar en Macul... y entre ésos estaba yo y los cabros que yo metí, donde algunos llegaron a ser dirigentes del PS después. En esa época comenzamos con las mesas en el Paseo Ahumada a inscribir gente para el partido, jtodo un movimiento!, crear el comunal, etc., con lo cual mi actividad política estuvo ligada al trabajo territorial"23.
\end{abstract}

Esta primera etapa representa un referente importante para todos los militantes fundadores, un período que se recuerda como la etapa más efervescente e idealista del partido, un período donde había una cierta lógica de la lucha épica de la adhesión al PPD. Aquí germinaron liderazgos y se iniciaron carreras políticas en una apuesta bajo escenarios muy inciertos. La militancia PPD en este período es más similar al antiguo estilo de militar "comprometido", donde los militantes gerenciaban la campaña, salían de noche a pegar los afiches y construían las bases organizacionales sobre las cuales reposaría el partido en el futuro.

En consecuencia, que el PPD haya sido en su mayoría el socialismo renovado despeja parcialmente tres elementos importantes de nuestras preguntas de partida. Primero, que no es un partido totalmente nuevo pues gran parte de sus militantes y dirigentes pertenecían a otra matriz ideológica y política, por lo cual decir que es un partido nuevo sólo tiene sentido en términos cronológicos e institucionales ya que de otra forma se omite todo el proceso que permitió que la empresa fuese exitosa y llegara a constituirse ${ }^{24}$. En segundo lugar, si este partido fue la expresión del socialismo renovado, su carácter no ideológico queda en entredicho, puesto que su creación implicó en la práctica la puesta en marcha de ideas relacionadas con una reconsideración de la democracia y las alianzas políticas bajo la necesidad de abrir el socialismo hacia nuevos grupos. En tercer lugar, el componente nuevo de la militancia PPD ligado a los sectores de organizaciones sociales pudo haber sido efectivamente un espacio nuevo de militancia, pero muy limitado y cooptado por los militantes que provenían de otros partidos. Esto pudo haber llevado posteriormente a que la militancia en el PPD dejase los espacios "ciudadanos" para concentrarse en la política partidaria.

23 Testimonio de "F", militante del PPD desde su fundación. "F" Ilegó al partido gracias a su padre. Ha sido candidato a las elecciones internas del partido y su trabajo político se desarrolla a nivel territorial. Es periodista y funcionario público. Entrevista realizada en junio del 2007.

24 Michel Offerlé remarca la importancia de comprender los partidos políticos más allá de su momento constitutivo. Véase Offerlé (2002: 26). 


\section{La oportunidad política y la consolidación}

Para comprender el paso de proyecto transitorio a duradero, en el caso del PPD debemos considerar dos elementos de contexto. En primer lugar la caída del Muro de Berlín, que coincide con el retorno a la democracia en Chile y donde las reacciones de la izquierda fueron muy disímiles. Una posición más proclive al abandono del socialismo tradicional fue asumida por quienes deseaban hacer del PPD un proyecto de largo alcance superando el eje derecha-izquierda, para situarse en un nuevo eje articulador de posiciones políticas en relación al autoritarismo/democracia, aceptando el triunfo del mercado y de una sociedad plural. Eugenio Tironi, uno de los artífices de las estrategias de posicionamiento del PPD en sus primeros años, fue uno de los precursores de esta idea, lo que más tarde lo llevaría a considerar que la díada derecha-izquierda fue superada en Chile por una nueva fisura generativa en la díada autoritarismo-democracia (Tironi y Agüero, 1999) ${ }^{25}$. En segundo lugar, con la unificación del PS gracias a la derogación del artículo 8 de la Constitución que prohibía la existencia de partidos basados en la lucha de clases, el proyecto renovado se vio postergado bajo el rearme del PS en su vertiente más ortodoxa tras el Congreso de la Unidad Socialista Salvador Allende en 1991. En aquella ocasión muchos militantes del PPD decidieron no unirse al PS y seguir una senda propia. Para resolver este impasse, se mantuvo la doble militancia PS-PPD por un plazo de dos años, en el cual se debía optar por uno u otro partido.

Una buena parte de los socialistas ya unificados se quedaron en el PPD en el intento de hacer de éste un "brazo ciudadano" del PS; no lo concebían como un partido sino como un "movimiento" (Arrate y Rojas, 2003: 474) que interpretaba a los nuevos sectores progresistas no ligados a la izquierda tradicional y a la expectativa del surgimiento de nuevas posturas menos ideologizadas. Se esperaba que este nuevo electorado fuese el nicho específico del PPD. Asimismo, algunos se quedaron en el PPD considerando que era una buena estrategia para no ceder espacios a la DC y ampliar el bloque de izquierda de la Concertación hacia el centro mientras se producía la renovación del PS, de forma más lenta (Kaiser, 1998: 49).

Dentro de este contexto existen ciertos factores internos al PPD que configuran su dinámica de reproducción como la consolidación de los espacios sociales ligados al trabajo territorial, la apertura hacia sectores con bajo capital político inicial, considerados "no históricos"26, y la aparición de nuevos liderazgos. Con su creación el PPD se había desplegado en todo el territorio nacional y comenzaba a dar señales de un cierto poder más allá del PS, por cierto con nuevos líderes que de no ser por el PPD no habrían tenido cabida en la política de esos años. El trabajo en los comunales fue esencial para construir redes duraderas en el partido por medio de organizaciones sociales, sobre todo a nivel metropolitano donde el partido tiene su mayor base de apoyo.

25 Retomaremos esta idea en la tercera parte del trabajo.

26 Consideramos "no históricos" a quienes no tuvieron un nivel de participación importante en la política durante el gobierno de Allende y durante la clandestinidad en dictadura, ni formaban parte de las cúpulas dirigentes de los antiguos partidos de izquierda, pero que sin duda tenían algún capital político que aportar al PPD. 
La oportunidad electoral que presentaba el PPD de cara a las municipales de 1992 no fue nada despreciable. Su relación con el PS que permitía la doble militancia ofreció espacios de candidaturas para quienes se les hacía difícil entrar en la repartición de los cupos y en las designaciones dentro de la burocracia partidaria y del "micropoder" en el PS. Como ilustra el siguiente testimonio de un militante, el PPD constituyó un espacio alternativo para quienes no fueron nombrados en el PS, dando una justificación práctica a la permanencia en el PPD más allá de la convicción ideológica:

"Nos quedamos en el PPD por cuestiones coyunturales, que tienen que ver con el tema eleccionario, que tienen que ver con la primera elección que hubo retornada la democracia (...) se da un escenario donde el PPD estaba constituido legalmente y no habían candidatos (...) y ahí, en procesos internos para escoger candidatos del PS, la tendencia que lideraba mi viejo en esos momentos ve que el PPD estaba ahí, virgen, no había nadie y en el PS sí había competencia al interior, entonces en una conversación al interior de los dos o tres lotes que habían en el PS, resuelven que: 'pero mira, no llevemos uno (candidato), mejor ustedes vayan por el PPD'. Perfecto, entonces nosotros tomamos las banderas del PPD y nos fuimos con el PPD y quedamos con la doble militancia y así fueron los dos candidatos" 27 .

Igualmente, la composición diversa abrió un espacio social diferente al PS, donde tener un origen de "dirigente no político" o "no ser histórico" no era un hándicap, ya que se consideraba que el partido se conformaba por la movilización del capital político que cada uno traía de experiencias anteriores, y por supuesto cada miembro de organización traía votos y militantes para el partido desde sus propias bases. La apertura inicial que tuviera el partido hacia todos quienes quisieran luchar contra la dictadura sin importar su pertenencia ideológica -aunque en la práctica haya llegado principalmente gente del socialismo renovadomostró que para entrar al PPD y optar a alguna posición de poder, lo principal era el aporte de "capital" con el cual se llegaba, ya sea de dirigente social, estudiantil, gremial, político o con cierta visibilidad pública:

“Entré al PPD porque ya en esos años (1990-1993) se decía que entrar al PS si tú no eras histórico no te pescaban ni por apunte... pero en el PPD no "ser puro" no era terrible, al contrario, se suponía que tú tenías una historia, una trayectoria (...) el entrar al PPD en el 94 fue como un reconocimiento a mi historia. Todo el mundo decía: sí, ella 'viene de' ... ella estuvo participando en tal o cual cosa, entonces había todo un reconocimiento a mi trabajo anterior y bueno les dije: muéstrenme el trabajo que tienen, lo que puedo yo hacer, etc. (...) Me pareció seductor esto que aquí yo fuera a encontrar un montón de diversas ideas" 28 .

27 Testimonio de " $\mathrm{F}$ ".

28 Testimonio de "P", ex militante del MAPU. Ha ocupado cargos ejecutivos en el PPD y es funcionaria del sector privado en el área de la salud. Entrevista realizada en junio del 2007. 
El cursus honorum en el PPD no es demasiado determinante para llegar a las estructuras de poder del partido, cargos de elección popular o puestos en el Estado. Es bien sabido entre los partidos políticos chilenos que es más fácil llegar a ser candidato del PPD que en otro partido si se dispone de un buen capital. Prueba de aquello es la apertura del partido a personajes públicos de la televisión o del campo artístico que desean emprender una incursión en política como "profanos"29. La condición de profano al campo político también puede darse por una falta de capital simbólico dada la condición de "no-histórico", capital que se obtiene y se hereda a través de las familias de militantes que traspasan redes y prestigio a sus descendientes que continúan en política. En consecuencia, provenir de un mundo relativamente ajeno a los partidos y pretender iniciar una carrera política requiere estrategias de instalación en espacios menos disputados, más flexibles y ajustados al capital que se tiene. EI PPD fue durante los años noventa un espacio bastante abierto para acoger a "emprendedores" de la política, quienes pudieron encontrar allí una estructura más flexible para crear su propio espacio político. Así, es frecuente encontrar en el PPD un perfil de cuadro político-profesional de nivel medio, incluso de alto nivel jerárquico, que no proviene de los espacios históricos de la izquierda. Generalmente desde la condición de dirigente universitario han logrado posicionarse en el partido logrando desarrollar en el PPD rápidas y brillantes carreras como jefes de gabinete, directores de servicios públicos o subsecretarios durante los gobiernos de la Concertación. El fragmento siguiente representa un caso típico de este perfil que llega al PPD en un contexto de oportunidad ante una estructura partidaria más flexible:

"Yo no tengo ni historia de familia socialista ni tengo la historia que muchos socialistas tienen que defender, que es la lucha obrera, la lucha de fines del siglo XIX comienzos del $X X$, es un fenómeno mucho más tradicional que el que Chile hoy día (en esos años) el 94, 95, estaba ofreciendo, que era el PPD, entonces opté por eso. Además toda la figura de Lagos era una cosa muy interesante, yo te diría que Lagos y otros... pero claramente la opción de adscribir a un partido político era consciente, racional, que yo era un ser de izquierda, pero instrumental desde el punto de vista de la oportunidad política en que yo estaba optando por el PPD. Porque me parecía que como instrumento de la izquierda en Chile, el PPD en el 97 cuando firmé, era un brazo mucho más interesante para intervenir la sociedad chilena, tenía más alto el techo, por así decirlo, tenía mayor posibilidad de crecimiento" ${ }^{\prime \prime}$.

29 Tres diputados del PPD han sido actores de televisión: Ramón Farías, Ximena Vidal y Álvaro Escobar. También un ex alcalde, Santiago del Campo, fue presentador de reportajes en televisión. Para las elecciones municipales en el 2008 el partido optó por abrirse a los "nuevos líderes sociales" y "ciudadanizar" las candidaturas nombrando candidatos profanos o semiprofanos a la política, entre quienes se encontraban varios independientes considerados de "la farándula", como una ex vedette, una actriz de televisión y un futbolista.

30 Testimonio de "H", militante del PPD desde 1996. Se integró como dirigente universitario a la juventud del PPD y ha desarrollado una rápida carrera como alto asesor de diferentes ministros. Entrevista realizada en abril del 2007. 
El PPD ha buscado siempre candidatos con cierto reconocimiento social por sus actividades en diferentes campos y que puedan ser electoralmente atractivos. Aunque la mayor parte de los candidatos electos del partido son individuos iniciados y profesionales de la política, no es equívoco señalar que el PPD es el partido más abierto a los "profanos" al campo político, reconocidos por el PPD como "ciudadanos".

El posicionamiento del PPD en el Estado o la participación en el spoil system como un partido en igualdad de derechos comenzó en 1993 cuando, una vez separado del PS, alcanza una votación exitosa en las parlamentarias de 1993. En los años noventa un nuevo grupo de dirigentes relativamente jóvenes comienza a tomar fuerza bajo ciertos temas nuevos que el PPD planteaba y que le dieron su carácter distintivo en su primera etapa. Temas como el medio ambiente, el género, los pueblos originarios, la defensa de los consumidores, la modernización económica y cultural, etc., no precisamente enfocados a un sector popular del electorado, lograron hacer visibles a dirigentes como Guido Girardi, Jorge Schaulsohn, Nelson Ávila, Carolina Tohá y María Antonieta Saa. Se adoptó en estos años un estilo fuertemente mediático, con un enfoque de denuncia y un rol fiscalizador que pareció ser una propuesta innovadora y eficiente para capturar al electorado, ya que su votación se incrementó paulatinamente hasta superar al PS como se muestra en el Cuadro 5 tomando como referencia las elecciones de diputados.

\section{CUADRO 5}

Evolución de resultados electorales por partido político en elecciones de diputados entre 1989-2009

\begin{tabular}{|l|c|c|c|c|c|c|}
\hline \multicolumn{1}{|c|}{ PARTIDO } & 1989 & 1993 & 1997 & 2001 & 2005 & 2009 \\
\hline DC & $25,9 \%$ & $27,1 \%$ & $22,9 \%$ & $18,2 \%$ & $20,7 \%$ & $14,2 \%$ \\
\hline PPD & $11,5 \%$ & $11,8 \%$ & $12,5 \%$ & $12,7 \%$ & $15,4 \%$ & $12,6 \%$ \\
\hline PS & $*$ & $11,9 \%$ & $11,5 \%$ & $10 \%$ & $10,4 \%$ & $9,8 \%$ \\
\hline Partido Radical Social Demócrata (PRSD) & $3,9 \%$ & $2,9 \%$ & $3,1 \%$ & $4 \%$ & $3,5 \%$ & $3,8 \%$ \\
\hline Unión Demócrata Independiente (UDI) & $9,8 \%$ & $12,1 \%$ & $14,4 \%$ & $25,1 \%$ & $22,3 \%$ & $23,5 \%$ \\
\hline Renovación Nacional (RN) & $18,3 \%$ & $16,3 \%$ & $16,7 \%$ & $13,7 \%$ & $15,9 \%$ & $17,8 \%$ \\
\hline PC & $*$ & $4,9 \%$ & $6,8 \%$ & $5,2 \%$ & $5,1 \%$ & $2 \%$ \\
\hline Partido Humanista (PH) & $0,7 \%$ & $1 \%$ & $2,9 \%$ & $1,1 \%$ & $1,6 \%$ & $1,4 \%$ \\
\hline
\end{tabular}

Fuente: Elaboración propia en base a resultados electorales disponibles en el sitio web del Gobierno de Chile: www.elecciones.gov.cl 
Durante la administración de Eduardo Frei Ruiz-Tagle, el PPD tuvo una notoria presencia en el Ejecutivo, logrando instalar sus cuadros y dirigentes en importantes ministerios, desplegando redes de trabajo en las comunas, fortaleciendo su rol de centro al interior de la Concertación y engrosando su número de afiliados que asciende hoy en torno a los 112.000. Sin embargo, se estima que no son más de 2.000 los verdaderamente activos que concurren a las elecciones internas del partido. Con todo, ello significaría un franco proceso de expansión que finalmente llegaría a su consolidación con la ascensión de Ricardo Lagos, su fundador, a la presidencia de la República en marzo del año 2000.

En el tránsito hacia la consolidación es importante notar que el compromiso de los militantes del PPD se hace más estrecho en términos organizacionales, en la defensa tanto de los espacios y beneficios conquistados en lo simbólico y lo material, como ha dicho el ex ministro Francisco Vidal, una de las figuras destacadas del PPD que comenzó su carrera como encargado de organizar al partido en la comuna de Las Condes: “(...) uno después se mete en la cuestión más psicológica, de tratar de defender el espacio que uno ha colaborado en construir" (entrevista a Francisco Vidal, en Kaiser, 1998: 91).

Podemos ver en el Cuadro 6 que entre los encuestados en el 2006 las "tareas clásicas de la militancia" o "repertorios militantes" (Lefebvre y Sawicki, 2006: 192) se mantienen en cierto grado, como el trabajo puerta a puerta en campañas y la captación de adherentes; sin embargo, en menor grado la preparación de folletos y afiches, tareas que cada vez están más externalizadas hacia agencias fuera del partido. Pero paulatinamente el partido comienza a transformarse en un espacio donde los más comprometidos son aquellos que gozan de cargos públicos, quienes a la vez sostienen financieramente al partido, lo cual señala un punto relevante de las transformaciones del compromiso político.

\section{CUADRO 6}

Repertorio militante en el PPD al 2006

\begin{tabular}{|l|c|c|c|c|c|c|}
\hline & $\begin{array}{c}\text { DESARROLLÓ } \\
\text { COMUNICADOS, } \\
\text { AFICHES, } \\
\text { FOLLETOS O } \\
\text { PÁGINAS WEB } \\
\text { DEL PARTIDO }\end{array}$ & $\begin{array}{c}\text { INTENTÓ } \\
\text { CONVENCER } \\
\text { PERSONAS DE } \\
\text { VOTAR POR } \\
\text { CANDIDATOS } \\
\text { DEL PARTIDO }\end{array}$ & $\begin{array}{c}\text { HIZO “PUERTA } \\
\text { A PUERTA" } \\
\text { POR UN } \\
\text { CANDIDATO(A) } \\
\text { DEL PARTIDO }\end{array}$ & $\begin{array}{c}\text { DONÓ } \\
\text { DINERO } \\
\text { PARA EL } \\
\text { FINANCIAMIENTO } \\
\text { DEL PARTIDO }\end{array}$ & $\begin{array}{c}\text { NAPTÓ } \\
\text { ADHERENTES } \\
\text { O } \\
\text { MILITANTES } \\
\text { PARA EL } \\
\text { PARTIDO }\end{array}$ & $\begin{array}{c}\text { ORGANIZÓ } \\
\text { CAMPAÑA } \\
\text { DESDE } \\
\text { EL NIVEL } \\
\text { LOCAL }\end{array}$ \\
\hline Nunca & $6,7 \%$ & $1,2 \%$ & $2,1 \%$ & $4,6 \%$ & $3,3 \%$ & $4,1 \%$ \\
\hline A veces & $22,5 \%$ & $14,1 \%$ & $13,7 \%$ & $21,2 \%$ & $33,2 \%$ & $15,8 \%$ \\
\hline $\begin{array}{l}\text { Con } \\
\text { frecuencia }\end{array}$ & $17,5 \%$ & $72,6 \%$ & $74,3 \%$ & $49,0 \%$ & $46,1 \%$ & $61,0 \%$ \\
\hline No responde & $53,3 \%$ & $12,0 \%$ & $10,0 \%$ & $25,3 \%$ & $17,4 \%$ & $19,1 \%$ \\
\hline
\end{tabular}

Fuente: Encuesta a Consejeros del PPD, Proyecto FONDECYT 1061034. 
En cuanto al rol de los miembros del PPD en el sostenimiento financiero del partido, es importante mencionar que no existen cotizaciones obligatorias: los aportes monetarios están determinados por la condición del militante ligado al aparato estatal, sea éste funcionario público de confianza política, parlamentario u otra autoridad electa, quienes son beneficiados por el spoil system en orden al lugar que ocupa el PPD en el sistema de partidos. Entre autoridades de gobierno y funcionarios del Estado suman un 44,3\% de los ingresos. Considerando además el $31 \%$ que aportan los parlamentarios y los aportes de los miembros del partido residentes en el exterior que corresponden principalmente a los funcionarios diplomáticos, se nos presenta un partido en que prácticamente aportan sólo aquellos que reciben un beneficio directo traducido en cargos o para mantenerlos. El 52\% (Cuadro 7) de los consejeros y miembros de la directiva nacional son funcionarios públicos, situación que podría develar un alto grado de estatización de la militancia del PPD o de sus dirigentes, quienes en su gran mayoría sostenían financieramente al partido, como señala el Cuadro 8, al momento de la aplicación de la encuesta. Esta situación provocaría hoy, con el partido fuera del gobierno, serios problemas de financiamiento, ya que no existen cuotas obligatorias para los miembros.

El aporte financiero al partido está determinado por la calidad de funcionario público y, por lo tanto, beneficiado con los puestos en el Estado que otorga el PPD. Según nuestra encuesta, en el Cuadro 7 el 52\% de los consejeros y miembros de la directiva nacional son funcionarios públicos, situación que podría develar un alto grado de estatización de la militancia del PPD o de sus dirigentes, quienes, por otra parte, son los que más contribuyen al financiamiento del partido, como se puede apreciar en el Cuadro 8.

\section{CUADRO 7}

Miembros del Consejo Nacional del PPD y miembros de la Directiva Nacional empleados por sector

\begin{tabular}{|l|c|}
\hline \multicolumn{1}{|c|}{ SECTOR DONDE TRABAJA } & PORCENTAJE \\
\hline Sector público & 52,6 \\
\hline Empresas privadas & 9,5 \\
\hline Organizaciones sin fines de lucro & 3,7 \\
\hline Trabajadores independientes & 14,1 \\
\hline Otros (desempleados, estudiantes, pensionados, no responde) & 10,6 \\
\hline No responde & 9,1 \\
\hline Total & 100 \\
\hline
\end{tabular}

Fuente: Encuesta a Consejeros del PPD, Proyecto FONDECYT 1061034. 


\section{CUADRO 8}

Estructura del financiamiento del PPD (2004-2005)

\begin{tabular}{|l|c|c|}
\hline \multicolumn{1}{|c|}{ ESTAMENTO } & APORTE ANUAL (2004) & PORCENTAJE \\
\hline Autoridades de gobierno & $\$ 19.960 .624$ & 15,02 \\
\hline Militantes en el gobierno & $\$ 39.030 .600$ & 29,34 \\
\hline Militantes fuera del gobierno & $\$ 7.685 .500$ & 5,80 \\
\hline Parlamentarios & $\$ 42.390 .000$ & 31,90 \\
\hline Militantes en el exterior & $\$ 23.827 .235$ & 17,93 \\
\hline Total & $\$ 132.868 .959$ & 100 \\
\hline
\end{tabular}

Fuente: Información proporcionada por la Unidad de Finanzas y Recaudación PPD (2005, y corroborada en el 2008).

Es interesante ver que muy pocos encuestados se desempeñan en el tercer sector o en organizaciones sin fines de lucro, hecho que contrasta con la visión de un partido de "ciudadanos" y la supuesta integración de gente del mundo de las organizaciones sociales al PPD. Esto nos Ileva a comprender que el PPD es esencialmente un partido dirigido por funcionarios públicos de mandos medios y altos y trabajadores independientes, muy semejante al perfil de los partidos socialdemócratas europeos.

La composición socioprofesional del PPD al año 2006, 19 años después de su fundación, nos muestra que han ocurrido interesantes cambios que señalan el perfil más actualizado de esta colectividad con relación a su momento fundacional. A pesar de que no corresponde al mismo tipo de muestra, si tomamos como referencia el acta de fundadores del partido y su composición socioprofesional (Cuadro 4), veremos que en la actualidad el PPD sigue siendo un partido en el cual los grupos susceptibles de pertenecer a los estratos medios y acomodados de la sociedad constituyen el grueso de su dirigencia: $67 \%$, como se deduce del Cuadro 9. Es interesante notar que es posible que haya aumentado la cantidad de miembros con profesiones liberales, que esta vez es considerablemente mayor a las de carácter intelectual: 34,7\% contra $17,6 \%$ en 2006 versus $24,3 \%$ contra $34,2 \%$ en 1987 , respectivamente. Una explicación posible de aquello es que el éxodo de militantes en el año 1992 al terminar la doble militancia hizo que muchos cuadros intelectuales regresaran al PS, provocando que en el PPD comenzaran a refugiarse principalmente profesionales de perfil más técnico, "pragmáticos", si se puede decir de algún modo. Aunque plausible, este punto es aún una hipótesis que sin embargo nos permite identificar cierta capacidad del partido para captar profesionales provenientes de campos como el derecho, la economía y la ingeniería, fortaleciendo un perfil técnico de sus cuadros. 


\section{CUADRO 9}

Composición socioprofesional de los cuadros dirigentes del PPD en el 2006

\begin{tabular}{|l|c|}
\hline \multicolumn{1}{|c|}{ PROFESIONES/ESTRATOS } & PORCENTAJE \\
\hline Empresarios y gerentes & 2,6 \\
\hline Profesiones liberales & 34,7 \\
\hline Profesiones intelectuales & 17,6 \\
\hline Profesores universitarios & 1,06 \\
\hline Artistas y cultura & 0,53 \\
\hline Profesores & 10,6 \\
\hline Comerciantes-microempresarios & 2,1 \\
\hline Empleados & 9 \\
\hline Técnicos y cuadros intermedios & 19,2 \\
\hline Artesanos & 1,06 \\
\hline Obreros empleados de servicio & 1,06 \\
\hline Pobladores & 100 \\
\hline Total respuestas validas & 0 \\
\hline
\end{tabular}

Fuente: Encuesta a Consejeros del PPD, Proyecto FONDECYT 1061034.

Los dirigentes de estratos medios también pueden haber sufrido cambios, sobre todo en el considerable aumento de la cantidad de técnicos y cuadros intermedios que constituyen el $19,2 \%$ de la dirigencia, un aumento de un $12,9 \%$ respecto al año 1987 . Ello puede representar el desarrollo de espacios partidarios para los profesionales intermedios, que se insertan principalmente en el aparato público, calzando coherentemente con la etapa de despliegue del partido en los puestos de la administración pública a partir del gobierno de Frei.

Los cambios marginales, sin embargo no menos interesantes, nos indican que existe un pequeño número de dirigentes provenientes del mundo empresarial, que son los nexos con un sector aparentemente alejado del progresismo, prestando una utilidad concreta al partido. Por otra parte, en el partido disminuye la presencia de componentes populares en su dirigencia en un $3,4 \%$ respecto a su fundación, situación que de todas formas no varía 
su perfil de partido que nunca fue representante, en términos reales de integración de clase, de los sectores populares en Chile.

La combinación de factores que dieron vida propia al PPD nos hablan de que las organizaciones, más allá del deseo de sus miembros y de los discursos fundantes que anuncian transitoriedad o instrumentalidad, permanecen gracias a las dinámicas sociales que se generan con la movilización de recursos políticos, monetarios, sociales y los factores del contexto. Con el beneficio que nos da la distancia de los hechos, pensar que el PPD estaba destinado a desaparecer era bastante ingenuo, ya que se había respondido a una necesidad de un sector político importante de la renovación socialista y se había convertido en una conveniente opción para aquellos que no disponían del capital político suficiente para reclamar posiciones en el PS o en otros partidos.

En consecuencia, consideramos que el paso de partido transitorio a partido permanente se produjo bajo una lógica de la oportunidad en la medida que las tareas de la consolidación requieren mayores grados de compromiso con el partido en términos orgánicos, lo que ofrece a la vez retribuciones materiales inmediatas ligadas a la carrera política y la toma de los puestos disponibles para el PPD. Esta lógica de la oportunidad fue sobrepasando paulatinamente la lógica inicial de la lucha épica relacionada con retribuciones simbólicas, quedando esta última relegada hoy a la explicación del momento fundacional del partido y de su razón de ser en la lucha por la democracia durante la transición.

El Cuadro anterior otorga al PPD ciertas características de "partido cartel" (Katz y Mair, 1995) dado el alto grado de estatización de su militancia y su alejamiento de los sectores de la sociedad civil en el cual estaba inserto en un comienzo, dando paso a un evidente proceso de profesionalización. Frederik Bailey (1971) ha subrayado que en los grupos políticos cohabitan a la vez equipos morales y equipos contractuales, los primeros movilizados por valores (o retribuciones simbólicas) y los segundos por beneficios materiales; en este sentido, la noción de partido cartel daría cuenta sólo de una dimensión contractual y por lo tanto parcial de la militancia PPD, lo que nos orienta a buscar la dimensión moral o ideológica para completar nuestra visión.

\section{LA CUESTIÓN DE LA IDEOLOGÍA DEL PPD}

El mito del PPD como un partido sin ideología, a pesar de no tener una base sociológica real, es un problema de importancia considerable en el partido, ya que este supuesto se ha instalado fuertemente entre sus miembros generando representaciones artificiales sobre la ideología del PPD. La discusión partidaria -bizantina- en este ámbito se ha concentrado más bien en un juego de etiquetas poco fructífero entre liberales, socialdemócratas o progresistas "a secas". Por otra parte, la poca discusión académica que ha existido sobre este partido decide omitir este punto, asumiendo al PPD como un partido sin ideología y punto. Pero de ninguna manera se aprecia la forma que pueden tomar ciertas ideologías presentes en el partido y como éstas explican la acción política (Sartori, 1969) y sus efectos en la organización. 
Sostenemos que el PPD no tiene una diversidad ideológica atomizada, como se pensaba en un principio, o que lo distancie demasiado de la diversidad existente en el PS donde también se encuentran liberales, cristianos, marxistas, socialdemócratas, etc. Las posturas del PPD como "partido sin ideología pero de valores" o "partido ciudadano" son más bien "estrategias de presentación" que estructuran una puesta en escena según la voluntad de los dirigentes, pero que poco tienen que ver con lo que piensan o creen los miembros del partido. Esta estrategia de presentación, lejos de ser una fórmula neutral de unidad y diversidad, ha sido generadora de fragmentaciones y problemas de identificación con el partido. Ello no gracias a su carácter neutral sino a su dimensión institucional implícita que conlleva una visión emancipada de la vida partidaria omitiendo, entre otras cosas, espacios de sociabilidad partidaria en torno a una visión ideológica compartida.

\section{¿Pragmáticos?}

Cuando el PPD enfrenta las elecciones parlamentarias de 1993 -ya separado del PScomienza a establecer un nuevo perfil. Intenta darse forma como partido político totalmente autónomo del PS y plantea una declaración de principios en la cual se define como un partido sin ideologías, más bien de ideas, valores y programas, un partido constituido por distintas tradiciones políticas como el liberalismo progresista, el cristianismo popular, el socialismo democrático y el humanismo laico: "Algunos nos objetan que somos un partido sin ideología. Es cierto, nuestra opción es ser un partido de ideas y no de ideologías. Rechazamos las visiones totalizantes e integristas de la vida y la sociedad" (Bitar, 1993: 13).

Hasta hoy, los dirigentes del PPD nunca han querido profundizar en la adopción de una doctrina política más específica; sin embargo, en 1998 se redacta un "ABC Doctrinario" para hacer frente a las críticas ante la falta de doctrina y para dar orientación a los militantes. Era una especie de manual estilo catequesis con preguntas y respuestas sin ningún trasfondo ni discusión teórica sólida, pero totalmente clarificador sobre lo que el PPD promueve como ideas para el país. Tal documento fue elaborado por la Secretaría de Capacitación ${ }^{31}$ del partido y una de sus ideas fuerza estaba en que el PPD no era un "partido pragmático" sino que tenía principios. Pero el mismo concepto de "pragmatismo" parece no estar claro o completamente consensuado al interior del partido, ya que importantes dirigentes como Pepe Auth y Sergio Bitar han declarado el carácter pragmático del partido contradiciendo la declaración de principios y el "ABC doctrinario" que el mismo Bitar firmara cuando fue presidente del partido:

“Nuestra diferencia está en los 'pecados de origen', que es el de un pluralismo mayor, una diversidad más extendida, la combinación de un cierto radicalismo cultural y social con un cierto pragmatismo político, es decir, la capacidad para buscar acuerdos y ser factor de

31 Es curioso notar el nombre "capacitación" dado a la secretaría encargada de la difusión de la doctrina del partido, más bien destinada a la formación de competencias. Esta secretaría se llama hoy "Educación Política" en un intento por darle un carácter menos instrumental. 
unidad y de solución política allí donde otros se ven atrapados en sus esquemas ideológicos o rigideces orgánicas" (entrevista a Pepe Auth, en Kaiser, 1998: 21).

“(...) nació (el PPD) como partido instrumental y se quedó en la vida política como partido pragmático, no ideológico" (Bitar, 2007: 64).

Vemos aquí una doble interpretación del "pragmatismo". Por un lado basada en las representaciones sociales de la militancia y los detractores del PPD, donde el pragmatismo es sinónimo de falta de principios, de ideales, de "poder por el poder" y en consecuencia constituye una traición al pensamiento de izquierda. Esta visión daría la imagen del PPD como una "máquina partidaria", ante lo cual la Secretaría de Capacitación reaccionó refutando pero no reivindicando una forma correcta de pragmatismo. Por otro lado, desde una perspectiva más reducida ${ }^{32}$ están las concepciones de los dirigentes quienes ven al pragmatismo como una "forma mejorada" de visión política, menos anclada en el pasado y proclive a los cambios y a la flexibilidad que requiere gobernar en democracia, un pragmatismo de ideas que se trasunta en un pragmatismo político ${ }^{33}$.

Ante las incongruencias internas sobre las concepciones del "pragmatismo", el concepto que parece haber tenido mayor aceptación en los usos del lenguaje simbólico en el PPD es el concepto de "progresismo". A semejanza de la doctrina masónica del "Gran Arquitecto del Universo" como forma genérica de Dios para que hombres de diversa religión se junten a discutir sobre la búsqueda de la verdad sin pelearse sobre el nombre de Dios, la idea de "progresismo" reemplazó en el PPD al concepto de izquierda en términos doctrinarios. Así, todos aquellos que llegaran al PPD desde distintas vertientes podrían trabajar unidos en torno a un programa político y ciertas metas electorales. Sin embargo, como hemos visto en el Cuadro 2, examinando el origen en otros partidos políticos de los militantes del PPD, la diversidad política nunca fue extrema como para tener que dejar a un lado las doctrinas y crear una figura neutral para evitar conflictos ideológicos. Nuestra encuesta señaló que el $68,5 \%$ de los militantes del PPD provenía de partidos de izquierda y, del 25\% que no venía de ningún partido, el 57,9\% profesaba una o más doctrinas de izquierda.

Claramente, a partir de la separación del PS los dirigentes del PPD debían mostrar que se trataba de algo distinto; y ya que todo el socialismo renovado no permaneció en el PPD, sino que una parte importante regresó al PS, no podía atribuirse el monopolio de la renovación. Con todo, adhirieron a la socialdemocracia mediante el ingreso a la Internacional Socialista en 1995. Sin embargo, presentarse a nivel nacional como un partido socialdemócrata no parecía políticamente viable salvo en una especie de fusión o federación con el PS, lo que

\footnotetext{
Según la encuesta de Auth y Echeverría en 1993, sólo un 21,1\% de los consejeros se definió como pragmático. Esta concepción se ajusta un poco más a lo que planteara Sartori, quien considera el pragmatismo como un sistema de creencias en torno a lo político, sin embargo no necesariamente ideológico, en el sentido que un sistema de creencias de tipo ideológico tiene mayor resistencia a las pruebas empíricas, se concentra más en los fines y tiene un alcance universal. En cambio, el sistema pragmático es más abierto a la evidencia más allá de las "razones de la razón", se concentra en "los medios" y tiene un alcance más limitado hacia las esferas de la vida. Véase Sartori (1969).
} 
estaba rechazado a partir de 1990 y hasta hoy no encuentra asidero. Además la marca "socialdemócrata" estaba ya "patentada" por el Partido Radical Social Demócrata, por lo cual se debió buscar otro camino para distinguirse políticamente de sus socios.

Creemos que la renuncia a la definición doctrinaria fue hecha principalmente como una forma de crear artificialmente un espacio o clivaje del que no se estaba seguro de que existiera realmente. En términos de Erving Goffman (1973) esto fue una estrategia de presentación de sí destinada a la creación de una "fachada" que haga creer al público lo que se desea aparentar, en este caso una fachada que contribuyera a generar un espacio para el PPD en el sistema de partidos. Estas fachadas articuladas mediante unas puestas en escena no necesariamente son construidas deliberadamente con una intención de engañar o esconder lo verdadero de la organización. Al igual que las personas en la vida cotidiana, las organizaciones tienen igualmente una dimensión dramatúrgica que conlleva actos destinados a la autoafirmación y que producen un impacto real en la percepción de la situación tanto en los actores como en las audiencias, llevando a mitificaciones e idealizaciones.

A pesar de la ausencia general del debate ideológico en el PPD, la estrategia de presentación del partido estuvo acompañada de cierto sustento teórico a partir de la discusión en torno a la teoría de clivajes de Lipset y Rokkan (1967). La tesis de Tironi y Agüero respecto al surgimiento de un nuevo clivaje autoritarismo/democracia que nace en la dictadura y se prolonga en democracia sobrepasando el antiguo clivaje descrito por Valenzuela (1995) -izquierda/derecha, religioso/laico- daría cuenta de las preferencias políticas de la sociedad chilena de los noventa. Según Eugenio Tironi (ex militante y fundador del PPD) la sociedad chilena ya no reconocería estas antiguas divisiones, con lo cual los tres tercios "izquierda, derecha y centro" no tendrían sentido. Por el contrario, la configuración de bloques en torno a los hechos de la dictadura y la recuperación de la democracia configurarían un nuevo paisaje político. Así, los bloques representantes de este nuevo clivaje serían la Concertación y la Alianza, corroborado por la tendencia a la identificación del electorado con coaliciones antes que con partidos ${ }^{34}$.

Ciertamente, hoy la teoría de los clivajes está cada vez más en duda: los partidos de izquierda no están necesariamente destinados a representar a la clase obrera ni la derecha conservadora a los sectores acomodados. Sin embargo, hay que notar que cuando los encuestados dicen inclinarse más hacia una coalición que hacia un partido, es muy probable que tal inclinación esté determinada por el grado de interés en la política y por la competencia que se tenga para juzgar la contingencia. En efecto, para quienes la política es un mundo ajeno, resulta más fácil responder por una coalición que por un partido dado al grado de generalidad y simplificación de las ideas que presenta la figura de grandes antagonistas ${ }^{35}$.

34 Ver serie de encuestas CEP al respecto: www.cepchile.cl

35 Siguiendo esta propuesta de Tironi y Agüero, habría que pensar que en los años setenta la gente se habría inclinado más por un partido en específico dentro de la Unidad Popular (UP) que por la UP misma, por ejemplo. Esto nos parece fuera de lugar, ya que sobre todo para los sectores populares es siempre más fácil comprender la idea de una alianza que dominar los preceptos ideológicos de partidos específicos si no se está 
La anunciación de nuevos clivajes es a menudo una operación artificiosa, una estrategia de los partidos para designar, apropiarse o marcar territorio sobre un electorado específico mediante un proceso de construcción de representaciones sociales (Offerlé, 2002: 3233). En este sentido, podemos pensar que los dirigentes del PPD han querido presentar al partido como una organización que superaría la pugna ideológica de los años setenta y los antagonismos de clase: su propuesta sería adaptada a los temas contemporáneos de la sociedad chilena con nuevos electores.

Así, la visión del PPD como "partido ciudadano" fue fortalecida por Guido Girardi a la cabeza del partido entre los años 2000-2003, donde quiso implantar con fuerza esta concepción de partido como fórmula para dar representación a un nuevo clivaje; él mismo declara sobre este punto: "Yo siempre he tenido claro que, no sé si soy de izquierda, pero que no soy de derecha" (Girardi, en Kaiser, 1998: 67). La idea de Girardi apuntaba a crear una imagen de partido compuesto por diversos actores pertenecientes a organizaciones de la sociedad civil, quienes se reunían en el PPD para coordinar junto a dirigentes políticos las estrategias para alcanzar los objetivos ligados a los derechos de la mujer, el ecologismo, los pueblos originarios, los derechos de los consumidores, etc. Todo bajo una iconografía y una propuesta comunicativa rupturista, ligera y lúdica.

Una de las campañas que alcanzó el clímax de este estilo fue la municipal del 2004, donde el PPD presentó a sus candidatos disfrazados como superhéroes bajo el slogan "te defiende siempre", lo que para los más tradicionales era un verdadero vejamen al decoro político. Esta campaña fue justificada por el presidente del PPD de aquel entonces, Víctor Barrueto:

"Sí, el PPD desde que nació lo hizo con colores distintos, agregó colorido a la política chilena, y queremos hacerlo entonces de manera lúdica, entretenida, moderna, que marque diferencia, innovadora, rupturista si ustedes quieren, pero que puede entusiasmar hasta a los niños que van a andar felices con los superhéroes que defienden a la gente ${ }^{\prime \prime 36}$.

Por otra parte, esta estrategia de presentación del PPD fue elaborada como una manera de situar al partido en un espacio que se creía no ocupado por otros partidos, entre otras cosas dada la lenta evolución del PS hacia la renovación. Esta situación ya había generado al interior de la organización ciertas reticencias, puesto que la falta de doctrina se vio como una debilidad importante ${ }^{37}$. Hoy, con un PS muy distinto al de 1991, casi "ultra renovado", el PPD se ha quedado sin un discurso propio y su propuesta condenada más bien a una cuestión de estilo y estética organizacional. Incluso, el problema del espacio propio del PPD se agudiza más con la reciente presencia del Partido Progresista (PRO) de Marco EnríquezOminami, el que podría disputarle su lugar.

en familiaridad con ellos. Para mayor detalle sobre la formación de opiniones y disposiciones hacia la política, véase Gaxie (1978): Le cens caché.

36 Discurso pronunciado por Víctor Barrueto en el Castillo Hidalgo para el lanzamiento de la campaña municipal del PPD, el 22 de julio del 2004.

37 Según la encuesta de Auth y Echeverría (1993), un 59,9\% consideró la carencia de doctrina como una debilidad del partido. 
Al contrario de la imagen de partido diverso y con raíz en las organizaciones sociales, lo cierto es que hoy la identificación ideológica de los miembros del PPD es bastante homogénea y quienes no adhieren a ninguna ideología en específico son marginales. Como muestra el Cuadro 10, las influencias ideológicas que más reconocen los militantes en el presente son: socialdemócrata, socialista, humanista laica, humanista cristiana y liberal, siendo la socialdemócrata la más frecuente con una amplia ventaja. En el pasado (antes del PPD) las más frecuentes fueron la socialista, marxista leninista, humanista cristiana y en menor medida la socialdemócrata y humanista laica. Este predominio de las ideologías de izquierda en el pasado combinada con el humanismo cristiano es congruente con la matriz ideológica del grueso de los antiguos partidos de los militantes PPD: MAPU, PC, PS.

Como podemos ver en el Cuadro 11 donde se muestra la polivalencia de las ideologías en el presente, del 18,7\% que reconoce influencia del humanismo laico, 10\% reconoce a la vez influencia de la socialdemocracia. Del 11,6\% que reconoce tener influencia del humanismo cristiano, 4,6\% reconoce igualmente a la socialdemocracia y 2,9\% al socialismo; del $10 \%$ de quienes reconocen influencia del liberalismo, el 5,4\% considera también a la socialdemocracia y el 3,3\% al socialismo. Claramente, la perspectiva ideológica dominante es la doctrina socialdemócrata, fuertemente transversal a las demás.

Si bien es cierto que en parte importante (75\%) el PPD ha sido conformado por ex militantes de diferentes partidos, es curioso notar que no existen alineamientos respecto a estas pertenencias anteriores. No se produjo lo que se observó en el PS con la unificación de ortodoxos y renovados en 1991, matriz de la cual surgen las actuales tendencias en su interior. En el PPD más bien existen tendencias que en la jerga partidaria son Ilamadas corrientes, "lotes" o más sutilmente "sensibilidades", que están semiestructuradas ideológica y orgánicamente y que tienden a tomar un alto grado de personalismo del tipo faccionario.

Hay una dimensión de la ideología como "uso práctico", un juego de etiquetas, que escapa al fuero interno y que nos habla de un uso asociado sobre todo a líderes. Estos usos prácticos pueden ser más poderosos que la existencia de verdaderas identificaciones ideológicas al interior y constituyen elementos claves para la construcción de las "fachadas". Así, es importante notar que aunque la ideología liberal tiene una frecuencia muy marginal respecto a las otras, en la práctica los dirigentes del PPD han reconocido que en su interior hay dos grandes corrientes de pensamiento o tendencias ${ }^{38}$, la socialdemócrata y la liberal, y se ha entablado toda una discusión al respecto tratando de llegar a puntos de conciliación. Igualmente, sin una correspondencia comprobable de una estructura ideológica en torno al concepto de "ciudadanía" y partido ciudadano de Girardi, se habla de una corriente ciudadana en el PPD que en verdad no existe más allá de un discurso liderado por uno de los hombres más poderosos del partido.

38 Las tendencias, como las define Sartori, son un conjunto de actitudes que se cristalizan en opiniones, corrientes de pensamiento o disposiciones a actuar en política; algunas pasan a tener mayor solidez mediante la identificación más profunda, la concatenación de intereses y la organización estructurada y disciplinada, hasta Ilegar a constituir una fracción. Véase Sartori (2002). 
CUADRO 10

Influencia ideológica al 2006

\begin{tabular}{|l|c|c|}
\hline \multicolumn{1}{|c|}{ POSICIONAMIENTO IDEOLÓGICO } & ANTES & AHORA \\
\hline Anarquista & $3,1 \%$ & $0,4 \%$ \\
\hline Feminista & $5,1 \%$ & $6,2 \%$ \\
\hline Humanista cristiana & $19,4 \%$ & $11,6 \%$ \\
\hline Humanista laica & $10,2 \%$ & $18,7 \%$ \\
\hline Liberal & $3,1 \%$ & $10,0 \%$ \\
\hline Marxista leninista & $25,0 \%$ & $4,1 \%$ \\
\hline Marxista maoísta & $2,0 \%$ & $0,4 \%$ \\
\hline Marxista trotskista & $4,6 \%$ & $0,4 \%$ \\
\hline Socialdemócrata & $10,2 \%$ & $38,6 \%$ \\
\hline Socialista & $29,6 \%$ & $21,6 \%$ \\
\hline Otra & $1,5 \%$ & $2,9 \%$ \\
\hline
\end{tabular}

Fuente: Encuesta a Consejeros del PPD, Proyecto FONDECYT 1061034.

CUADRO 11

Ideologías más frecuentes cruzadas en el presente

\begin{tabular}{|l|c|c|c|c|c|}
\hline PRESENTE & $\begin{array}{c}\text { HUMANISTA } \\
\text { CRISTIANA }\end{array}$ & $\begin{array}{c}\text { HUMANISTA } \\
\text { LAICA }\end{array}$ & LIBERAL & SOCIALDEMÓCRATA & SOCIALISTA \\
\hline Humanista cristiana & - & $1,7 \%$ & $1,7 \%$ & $4,6 \%$ & $2,9 \%$ \\
\hline Humanista laica & $1,7 \%$ & - & $3,7 \%$ & $10,0 \%$ & $5,0 \%$ \\
\hline Liberal & $1,7 \%$ & $1,7 \%$ & & $5,4 \%$ & $3,3 \%$ \\
\hline Socialdemócrata & $4,6 \%$ & $10,0 \%$ & $5,4 \%$ & - & $5,4 \%$ \\
\hline Socialista & $2,9 \%$ & $5,0 \%$ & $3,3 \%$ & $5,4 \%$ & - \\
\hline
\end{tabular}

Fuente: Encuesta a Consejeros del PPD, Proyecto FONDECYT 1061034. 
Aunque existen estas tendencias en forma de facción, no representan en sí mismas un tema de debate fuerte al interior del partido; es más, la tendencia pasa a tomar el apellido de quien la conduce: girardismo, bitarismo, vidalismo, y otros, lo que no significa que en el PPD existan más personalismos que en otros partidos como tantos han afirmado majaderamente. Lo que sucede a nuestro juicio es que por lo débil de los mecanismos simbólicos y teóricos de la reproducción de las tendencias, éstas tienden a resaltar la acción y la imagen del líder del grupo. El siguiente testimonio de una dirigenta del partido que adhiere a una corriente o "lote" nos señala esta situación antes descrita:

\footnotetext{
"Yo creo que yo me siento socialdemócrata en este partido digamos, pero más de izquierda que mi propio 'lote', o sea yo soy del vidalismo, bitarismo, una mezcla rara digamos, en este partido al final uno nunca logra tener una discusión profunda sobre lo que significa eso. Yo creo que hemos definido dentro del lote y dentro del partido no sé cuantas veces lo que significa ser socialdemócrata, socialdemócrata de izquierda una cosa súper rara... o sea yo todavía no logro sentirme identificada en plenitud con el proyecto de sociedad que queremos... o sea eso va cambiando, yo siento que no hay claridad, yo siento que va cambiando en la medida que el país va cambiando"39.
}

Este predominio de los líderes en el PPD ha llevado a Huneeus (2002) a clasificar al PPD como un partido de "notables", un partido de los más tradicionales que describiera Max Weber (1964). Sin embargo, creemos que este término no es adecuado para el PPD por dos razones: la primera, porque Robert Michels (1982 [1911]) observó que tal fascinación y veneración por los liderazgos en los partidos es casi una regla y la inclinación a tomar los nombres en reemplazo de doctrinas es bastante recurrente, y por cierto observable en diferentes grados en todos los partidos. Por otra parte, el concepto de "notable" al que se refería Weber implica una capitalización de recursos y créditos obtenidos en otros campos sociales como el de la cultura, los negocios, la academia, etc., que hacen de los notables personajes de cierto estatus dentro y fuera de la política. Tal caso no aplica a los mandamases del PPD, quienes más que notables se han hecho "notorios" gracias a la política ${ }^{40}$.

La renuncia del PPD a la doctrina en su dimensión institucional conlleva un descuido de los mecanismos de reproducción de los sistemas de creencias tales como escuelas de formación política, ceremonias de ingreso de militantes, distribución de material de análisis político con la doctrina del partido, eventos culturales y de camaradería donde hay espacios para el intercambio de ideas, etc. El partido no tiene una política al respecto y las iniciativas de este tipo son completamente irregulares.

Esta carencia refleja dos aspectos importantes a tener en cuenta: el primero, un cierto temor que existía en los dirigentes desde la fundación del partido de caer en una rutinización de la cultura partidaria que podría llevar a adoptar estructuras rígidas de los partidos tradicionales (entrevista a Bitar, en Kaiser, 1998: 10). En segundo lugar, para evitar aquello se pensó en

39 Testimonio de " $\mathrm{P}$ ".

40 Para el análisis de la notabilidad y la notoriedad en política, véase Offerlé (2002). 
hacer la adhesión al PPD más libre, más emancipada e independiente de las estructuras del partido. Cada cual se ocupa de su ideología, la organización no tiene un rol central en ello y no pretende invadir las estructuras ideológicas de sus adherentes con nuevos elementos. Puesto que se asumía que quienes adherían al PPD eran de una línea más bien renovada, los esfuerzos no debían encaminarse en instalar una nueva línea ideológica, sino más bien en sumar las existentes. El siguiente testimonio de uno de los dirigentes del PPD nos ilustra en este punto:
“(...) mi vocación de carácter socialista en la que yo creía desde los tiempos de la Unidad Popular de Tomic, la verdad no sufrió grandes cambios del punto de vista de mi adscripción como persona, aunque sí choques o confrontaciones usuales con los discursos doctrinarios ideológicos tanto de la propia Izquierda Cristiana, que de pronto se radicaliza, o con un tipo de socialismo arcaico con el cual yo nunca combiné. Y por lo tanto, nunca he sentido que el PPD haya afectado fuertemente esa matriz ideológica-cultural, pero sí he sentido que se hace difícil construir una en el PPD y desde el PPD una nueva, eso sí es complejo... pero sí lo que he hecho es ir adaptándome a los procesos políticos, a veces con más pragmatismo y otras veces con menos pragmatismos, lo que son las intensidades de estos temas (sus temas de derechos humanos) y siempre buscando los espacios y el momento como ponerlos" 41 .

Ciertamente en los partidos más ideológicos existe la tendencia a la competencia por establecer ideologías o corrientes dominantes, sin embargo normalmente es la organización central la que actúa como eje ordenador de la cultura partidaria, y quién accede a ella la impone. En el caso del PPD vemos que no existe tal cosa: la ideología como parte de la cultura partidaria es un elemento que se deja en cierta medida a la libre iniciativa y ello puede ser la base de problemas de cohesión en el partido que se traducen en una falta de identificación ideológica de los miembros del PPD con el partido.

Si nos referimos a la identidad partidaria, creemos necesario tener en cuenta el alcance que hace Rogers Brubaker $(2001)^{42}$ sobre los distintos procesos que concurren para formar lo que en un "todo" se interpreta como identidad. En ello resulta clarificador que la "conexidad", entendida como el vínculo social estrecho que genera el sentimiento de grupo, presenta diferencias interesantes en distintos grupos de militantes y dirigentes. El hecho de que los miembros del partido compartan características comunes y tengan un sentimiento de tener algo en común o "comunalidad" no genera necesariamente grupalidad. Es la "conexidad"

41 Testimonio de "D".

42 Brubaker propone dividir el estudio de las identidades en compartimentos más pequeños que permitan observar fenómenos más claramente y explicarlos evitando hablar de la identidad en abstracto. Esta segregación lleva a analizar la "identificación" y "categorización" de los individuos, lo que implica caracterizar a unos respecto a otros y situarlos en un rango determinado. Esto nos conduce a señalar y describir a los agentes identificadores y categorizadores. Por otra parte, es necesario el estudio de la "autocomprensión" y la "localización social", es decir, la conciencia de lo que se es y de qué lugar se ocupa en el espacio social a nivel individual. Finalmente la comunalidad (atributos comunes a un grupo), conexidad (grado y forma de relacionamiento) y grupalidad (sentimiento de grupo) son los procesos mediante los cuales se explica el sentimiento de pertenencia y solidaridad grupal. 
ligada a las redes afectivas la que genera parte importante de este sentimiento de pertenencia. En los dos ejemplos que se muestran a continuación los entrevistados exponen problemas de identificación con el partido respecto a este punto. Las redes de sociabilidad y afectividad juegan un rol considerable a la hora de construir sentimientos identitarios con la organización más allá de la ideología:

"En la historia de mis amigos por afuera (del PPD) que son MAPU, tenemos una amistad
profunda, cariñosa, que podemos estar en distintos partidos, en distintas posiciones
muchas veces, pero hay una cosa que se gestó en dictadura que tiene que ver con lo que
te mantiene viva en política, y eso está más allá que acá. Y acá a mí me ha costado hacer
amistades (...) aquí somos compañeros, somos militantes" 43 .
"Para ser sincero siento al PPD más como organización social, como pertenencia a un grupo
dentro del PPD, como identidad en un grupo, porque lo ideológico es como muy diverso
y muy particular, como de cada uno. Uno empieza a tejer vínculos, a generar amistades,
sentimientos, lazos, afectos y creo que eso es lo que en la sociedad actual más pesa, lo
que prima, más que una cuestión ideológica como a lo mejor primaba antes, como a lo
mejor todo el accionar giraba en torno a ciertas miradas de sociedad, o avancemos en
construir esto, yo creo que eso se ha perdido mucho hoy en día" 44 .

Para "P" la falta de espacios de sociabilidad en el PPD impiden que pueda identificarse más profundamente con él, mientras que para " $\mathrm{F}$ " el partido antes que todo es una organización social donde ha construido afectos y amistades que lo hacen sentir parte de un subgrupo dentro del PPD que es su círculo de amigos. El aspecto ideológico como podemos ver aquí cobra una importancia secundaria en cuanto a lo que tradicionalmente se asocia a la identidad. Lo anterior no quiere decir que para los militantes la ideología o los valores sean poco importantes, sino que en el caso del PPD, para efectos de la cohesión interna, la ideología no es una variable explicativa. Las dinámicas de conexidad al interior del partido son las que pueden producir identificación organizacional y cohesión interna.

Así, un indicador importante de conexidad son las amistades al interior del partido, sobre lo cual la encuesta aplicada en el 2006 nos entrega datos importantes como se señala en el Cuadro 12. Primero, un 38,5\% de los encuestados considera que sus amistades frecuentadas son militantes del PPD, mientras el 61,4\% estima que sus amistades más frecuentadas se encuentran fuera del PPD. En segundo lugar, la división por cohortes nos señala que a medida que avanzan las edades, en la vinculación al PPD cobran mayor importancia las redes de amistad o familiares vinculadas al partido así como la influencia de los líderes (Cuadro 13). Por el contrario, el contexto político del momento cobra mayor importancia en los más viejos. Esto nos indica que en los períodos de baja politización, como en Chile durante los años noventa, las redes de sociabilidad son más determinantes para el ingreso a

43 Testimonio de " $\mathrm{P}$ ".

44 Testimonio de " $\mathrm{F}$ ". 
los partidos ${ }^{45}$. Ante la falta de estas redes, baja el nivel de adhesión y cambian los móviles del compromiso político, como vimos en la parte anterior de este trabajo.

La falta de espacios de sociabilidad que estaban presentes en antiguas organizaciones de la izquierda tradicional es un aspecto que muchos de los viejos militantes extrañan y que los nuevos reclaman, como escuelas de formación política, fiestas de camaradería, ceremonias de ingreso al partido, etc., toda una serie de rituales y espacios sociales mediante los cuales el compromiso político se reforzaba en los lazos sociales ${ }^{46}$.

\section{CUADRO 12}

¿Son sus amigos, y los conocidos que Ud. más frecuenta, militantes del PPD?

\begin{tabular}{|l|c|}
\hline \multicolumn{1}{|c|}{ CATEGORÍAS } & PORCENTAJES \\
\hline Generalmente no lo son & 17,8 \\
\hline Unos pocos lo son & 43,6 \\
\hline Aproximadamente la mitad lo son & 17,4 \\
\hline La mayor parte lo son & 19,9 \\
\hline Todos lo son & 1,2 \\
\hline Total & 100,0 \\
\hline
\end{tabular}

Fuente: Encuesta a Consejeros del PPD, Proyecto FONDECYT 1061034.

Por otra parte, entre los más jóvenes sin una experiencia política anterior quienes no sienten una identificación fuerte con el PPD pueden a la vez sentirse instados a iniciar acciones que podemos considerar como "empresas de identificación" 47 . Recogiendo la necesidad de generar referentes ideológicos y aprovechando la oportunidad que el partido facilita a los emprendimientos individuales, invierten su capital militante y político en la construcción de una tendencia o "grupo político" toda vez que han alcanzado una posición de poder o influencia que de alguna manera les permite aventurarse. En los casos siguientes de dos militantes que pertenecen a un mismo "grupo político",

45 Para un análisis de los ciclos de politización y compromiso político, véanse Tarrow (1993) e lhl (2002).

46 Este fenómeno parece ser bastante común en los partidos de izquierda que han perdido muchas de sus antiguas tradiciones a la vez que sus militantes de base. Para un análisis de este fenómeno en el caso del Partido Socialista francés, véase Lefebvre y Sawicki (2006).

47 Siguiendo el trabajo de Brubaker, podemos tomar el concepto de "emprendedores de la identidad" desarrollado en Yves Besson (1990) y Emmanuelle Saada (1993)- renombrándolo como "emprendedores de la identificación" para denotar el proceso de construcción de categorías ideológicas para la identificación del grupo. 
como ellos lo definen, vemos cómo pueden sentarse bases para la construcción de tendencias o facciones en torno a un sentimiento más allá de lo ideológico, sino esta vez generacional. Este punto nos orienta sobre cómo buscar generaciones políticas más allá de cohortes; sin embargo, hay que distinguir con cuidado la existencia real de generaciones políticas y un uso estratégico del concepto de generación como un arma retórica de emplazamiento político:

“No me siento plenamente identificado con lo que es el partido... me siento responsable de la construcción de una identidad. Yo siento, y quizás por eso entro al PPD, que yo entro sabiendo que esto era una 'majamama' y que uno busca el poder porque uno busca ayudar a construir una identidad en el PPD (...) en conversaciones con amigos, claro tenemos ese ideario, pero al final no hay una construcción política grupal, al final son como rollos personales, pero eso en definitiva no se trasunta en un proyecto político común y nos quedamos en una fase primaria, que es el sembrar" ${ }^{\prime 4}$.

"No tengo una identificación fuerte con el PPD, yo te digo, porque siento que la gran mayoría del PPD tiene intereses disímiles a lo que a mí me gustaría para el PPD y segundo, porque precisamente por mi historia política no tengo en absoluto ningún dogma por la estructura 'Partido por la Democracia'. Es una forma, un ejercicio político colectivo, que tiene una característica y un contexto determinado y ojalá una proyección determinada, pero como eso, puede ser otro en algún minuto. Lo que a mí me interesaría, que como generación política chilena postdictadura podamos construir un referente político de izquierda adecuado a lo que viene ahora y lo que viene ahora es una lucha por la igualdad, que no es nada nuevo en la izquierda, pero es en cierta medida un desafío de plasmar el éxito político de esta coalición con los más pobres. (...) Tienes dos opciones para lograrlo, o tomar la opción de pelear el poder interno, en este caso del PPD e intentar hegemonizar tu visión, si es compartida con otros, no autoritariamente, o si las condiciones políticas están, generar un proceso político distinto, que en mi ideal es un centro de referencia política único de centro izquierda en Chile" 49 .

Como muestra el Cuadro 13, son los más jóvenes quienes ingresan al partido gracias a las redes sociales de la familia, amigos y una importancia marcada de admiración a ciertos líderes. McAdam (1986) señala que ésta es una característica propia del reclutamiento de "bajo riesgo" en épocas de baja politización, donde quienes entran y se mantienen en los movimientos sociales lo hacen principalmente mediante mecanismos de control social de su entorno ligados a los "costos de no participar"; esto puede aplicarse igualmente a los partidos políticos.

48 Testimonio de "J", militante del PPD desde 1998. Comenzó como dirigente estudiantil y se integró al partido por medio de la Juventud del PPD. Entrevista realizada en mayo del 2007. 


\section{CUADRO 13}

Importancia de la influencia en escoger al PPD entre distintas cohortes*

\begin{tabular}{|l|c|c|c|}
\hline IMPORTANCIA (MUCHA) DE LA INFLUENCIA DE: & C 70 & C 80 & C 90 \\
\hline Miembros de mi familia & $2,7 \%$ & $7,9 \%$ & $15,0 \%$ \\
\hline Algunos amigos & $2,7 \%$ & $6,2 \%$ & $7,5 \%$ \\
\hline Contacto directo con algunos militantes del partido & $6,4 \%$ & $9,5 \%$ & $15,0 \%$ \\
\hline Personajes de la política que admiraba & $10,9 \%$ & $21,2 \%$ & $35,0 \%$ \\
\hline Líderes de mi iglesia & $0,9 \%$ & $2,1 \%$ & $2,5 \%$ \\
\hline Contexto político del momento & $58,2 \%$ & $51,0 \%$ & $37,5 \%$ \\
\hline La acción del partido en mi lugar de estudio o trabajo & $3,6 \%$ & $3,7 \%$ & $2,5 \%$ \\
\hline Mi experiencia trabajando en organizaciones distintas de partidos políticos & $21,8 \%$ & $22,0 \%$ & $22,5 \%$ \\
\hline Otro factor & $8,2 \%$ & $7,1 \%$ & $10 \%$ \\
\hline
\end{tabular}

Fuente: Encuesta a Consejeros del PPD, Proyecto FONDECYT 1061034.

*C70: Cohorte marcada por los sucesos de la Unidad Popular y el golpe de Estado de 1973, quienes hoy tienen más de 50 años.

C80: Caracterizada por los jóvenes que vivieron los procesos de transición a la democracia en una forma activa y que hoy tienen entre 38 y 49 años.

C90: Personas que vivieron su adolescencia y madurez en democracia y tienen hoy entre 27 y 37 años de edad.

Como hemos visto, el mito del partido sin ideología en el PPD no es más que una representación vaga de lo que ahí dentro sucede. Los miembros del PPD sí cuentan con preceptos ideológicos bastante cercanos entre ellos, por lo cual el discurso de la diversidad ideológica del PPD tampoco es real. Podemos vislumbrar que la problemática institucional del PPD hoy no reside en la falta de ideología, ya que tales sistemas de ideas más o menos dogmáticos existen en los miembros del partido. El problema reside en que no existen instancias formales para reproducir sociabilidad en torno a estas orientaciones ideológicas, con lo cual la identificación con el partido en su conjunto se debilita, dando paso a fraccionamientos y a la formación de grupos menos cohesionados entre sí.

\section{CONCLUSIÓN}

En las páginas precedentes hemos intentado mostrar que para el estudio de los partidos políticos es necesario identificar el conocimiento común y las representaciones sociales que se tienen sobre el partido, e intentar sobrepasarlas en la medida que éstas constituyen 
obstáculos para conocer en profundidad los fenómenos políticos. Asimismo, intentar revelar el por qué tales representaciones se han cristalizado y lo que existe detrás de ellas.

En nuestro caso de estudio ha quedado en evidencia que para explicarlo como fenómeno político es necesario desconfiar de los formatos normativos como son los conceptos de partido instrumental, partido sin ideología o partido ciudadano, por cuanto el PPD como organización social no escapa a los fenómenos generales de los partidos como la lucha por los puestos, la fabricación de ideologías, los personalismos, las facciones, etc. Por otra parte, la forma de reproducción del PPD, es decir, este paso de partido transitorio a partido duradero, centra nuestra mirada en las dinámicas intrapartidarias que generan expectativas, afectos, solidaridades y hábitos, que no necesariamente están conectados por un cordón ideológico como usualmente se considera, ni únicamente motivados por cálculos electorales. Se trata más bien de una combinación de ambos aspectos, lo que toma diferentes énfasis según el contexto sociopolítico. Esta forma de análisis nos entrega una perspectiva sobre la transformación del compromiso militante a partir de momentos de alta politización y efervescencia y posteriores períodos de consolidación y burocratización del poder.

El importante grado de estatización de la dirigencia implica una tendencia a la cartelización, pero no es posible hablar de un partido-cartel en el PPD ni ver esta tendencia únicamente como un uso utilitario del partido. Como hemos visto, la ideología está muy presente en la acción política de los militantes; sin embargo, identificamos un problema mayor ligado a la sociabilidad partidaria -parte esencial de la institucionalización y rutinización de las organizaciones políticas a lo cual el PPD renunció deliberadamente desde su fundaciónque resta coherencia a la organización en relación a la identidad y la cohesión interna.

En consecuencia, el PPD fue un intento inacabado de "nueva militancia" que intentó instaurar una visión política desde los actores extrapartidarios, sin embargo en su camino a la consolidación inevitablemente avanzó hacia la profesionalización política pero dejando de lado la institucionalización de las prácticas de sociabilidad, lo que lo convierte en un proyecto político híbrido e inacabado.

\section{BIBLIOGRAFÍA}

Alcántara, Manuel (2001): "El origen de los partidos políticos en América Latina", Working Paper, 187, Institut de Ciències Platiques i Socials, Barcelona.

Arrate, Jorge y Eduardo Rojas (2003): Memorias de la Izquierda Chilena 1850-2000, Tomo II, Ediciones B Chile, Santiago.

Bailey, Frederik (1971): Les règles du jeu politique, Presses Universitaires de France, París.

Barrueto, Víctor (2004): Discurso pronunciado en el Castillo Hidalgo para el lanzamiento de la campaña municipal del PPD, 22 de julio.

Besson, Yves (1990): Identité et conflits au Proche-Orient, L'Harmattan, París.

Bitar, Sergio (1993): "Opciones y desafíos para el PPD", Partido Por la Democracia: Principios del Partido Por la Democracia, Serie Documentos Oficiales, Secretaría de Programas PPD, Santiago. 
(2007): Cita con la Historia. Entrevista de Patricia Arancibia Clavel, Editorial Biblioteca Americana, Santiago.

Bourdieu, Pierre (1981): "La représentation politique. Éléments pour une théorie du champ politique", Actes de la Recherche en Sciences Sociales, 36/37, pp. 3-24.

Brubaker, Rogers (2001): "Au-delá de l'identité", Actes de la Recherche en Sciences Sociales, 1/3, 139 , pp. $66-85$

Dalton, Russell J. y Martin P. Wattenberg (eds.) (2000): Partis without partisans, Oxford University Press, Oxford.

Duverger, Maurice (1990): Les Partis Politiques, Colin, París.

Gaxie, Daniel (1977): “Economie des partis et rétributions du militantisme", Revue Française de Science Politique, 27, 1, pp. 123.154

(1978): Le sens caché, Seuil, París.

(1980): "Les logiques du recrutement politique", Revue Française de Science Politique, 30, 1, pp. 5-45.

(2005): "Rétributions du militantisme et paradoxes de l'action collective", Swiss Political Science Review, 11 (1), pp. 155-188.

(2006): "Des penchants vers les ultra droites", en Annie Collovald y Brigitte Gaïti, (eds):

La Démocratie aux extrêmes. Sur la radicalisation politique, La Dispute, París, pp. 223-245.

Goffman, Erving (1973): La mise en scène de la vie quotidienne. La présentation de soi, Minuit, París.

Haegel, Florence (2007): "Le pluralisme à L'UMP. Structuration idéologique et competition interne", en Haegel, Florence (ed.): Partis politiques et système partisan en France, Presses de Sciences Po, París, pp. 219-284.

Huneeus, Carlos (2002): El PPD. ¿Partido moderno o simplemente partido de notables?, Centro de Estudios de la Realidad Contemporánea (CERC), Santiago, disponible en www.asuntospublicos. org/informe.php?id=258

(2007): "La Concertación está en un estado de perplejidad muy grande", entrevista en Diario La Nación, 2 de enero.

Ihl, Olivier (2002): "Socialisation et événements politiques", Revue Française de Science Politique, $52,2 / 3$, pp. 125-144.

Ion, Jacques (2007): "Mutations des engagements militants. Du timbre au post-it", CAES Magazine, 83, pp. 34-37.

Kaiser, Ximena (1998): "Confesiones verdaderas", Serie Contribución al Debate, 20, Partido por la Democracia, Santiago.

Katz, Richard y Peter Mair (1995): "Changing modes of party organization and party democracy: the emergence of the cartel party", Party Politics, 1 (1), pp. 5-28.

Kirchheimer, Otto (1966): "The Transformation of the Western European Party System", en Joseph LaPalombara y Myron Weiner (eds.): Political Parties and Political Development, Princeton University Press, Princeton, pp. 177-200.

Lefebvre, Rémi y Frédéric Sawicki (2006): La société des socialistes. Le PS aujourd'hui, Éditions du Croquant, París. 
Lipset, Martin y Stein Rokkan (1967): "Cleavage Structures, Party Systems, and Voter Alignments: An introduction", en Martin Lipset y Stein Rokkan (comps.): Party Systems and Voter Alignments: Cross-National Perspectives, The Free Press, New York, pp. 1-64.

Mannheim, Karl (1952): "The Problem of Generations", en Essays on the Sociology of Knowledge, Routledge and Kegan Paul, Londres, pp. 276-322.

McAdam, Doug (1986): "Recruitment to High-Risk Activism: The Case of Freedom Summer", The American Journal of Sociology, 92, 1, pp. 64-90.

Michels, Robert (1982 [1911]): Los partidos políticos, Amorrortu Editores, Buenos Aires.

Offerlé, Michel (2002 [1987]): Les partis politiques, PUF, París.

Olson, Mancur (1971): The logic of collective action, Harvard University Press, Boston.

Ostrogorski, Moisei (1912 [1903]): La démocratie et l'organisation des partis politiques, CalmannLévy, París.

Peña, Carlos (2006): Siete tesis sobre el PPD y la ética pública, presentación en el Consejo Nacional del PPD, noviembre, Santiago.

Saada, Emmanuelle (1993): "Les territoires de l'identité. Etre juif à Abreville", en Genèses, 11, pp. 111-136.

Sartori, Giovanni (1969): "Politics, ideology and belief systems", American Political Science Review, 63, 2, pp. 398-411.

(2002): Partidos y sistemas de partidos, Alianza Editorial, Madrid.

Scarrow, Susan (2000): "Parties without members", en Russell Dalton y Martin P. Wattenberg (eds.): Partis without partisans, Oxford University Press, Oxford, pp. 79-101.

Schmitt, Carl (1999 [1932]): El concepto de lo político, Alianza Editorial, Barcelona.

Tarrow, Sidney (1993): "Cycles of collective action: Between moments of madness and the repertoire of contention", Social History, 17 (2), pp. 218-307.

Tironi, Eugenio y Felipe Agüero (1999): “¿Sobrevivirá el nuevo paisaje político chileno?”, Estudios Públicos, 74, pp. 151-168.

Valenzuela, Samuel (1995): "Orígenes y transformaciones del sistema de partidos en Chile", Estudios Públicos, 58, pp. 5-77.

Weber, Max (1964 [1922]): Economía y Sociedad, Fondo de Cultura Económica, México. 